\title{
Shock Compression of Crustal Rocks: Data for Quartz, Calcite, and Plagioclase Rocks
}

\author{
Thomas J. Ahrens and V. G. Gregson, Jr. \\ Poulter Reasearch Laboratories, Stanford Research Institute \\ Menlo Park, California
}

\begin{abstract}
Hugoniot data in the 4- to $250-\mathrm{kb}$ stress range were obtained for quartzite and novaculite, sandstones of varying porosity, single-crystal calcite, marble, porous and nonporous limestone, several plagioclases of varying composition, and a basalt. Conventional plane-wave, in-contact explosive assemblies were used; the shock state was computed from measured shock velocities; particle velocities are inferred from either specimen or driver plate free-surface motion. Impedence-match solutions were obtained for porous rock. High values of the Hugoniot elastic limit were observed in nonporous rocks approximately 40 to $90 \mathrm{~kb}$ in quartzite and novaculite, 40 to $50 \mathrm{~kb}$ in the plagioclase rocks, and 15 to $25 \mathrm{~kb}$ in calcite and marble. Reduced values were found for porous rocks, approximately $5 \mathrm{~kb}$ in sandstone and limestone. Phase transitions are inferred at 30,45 , and $95 \mathrm{~kb}$ in calcite, and 22,45 , and $90 \mathrm{~kb}$ in marble and limestone. For calcite these are indicated by multiple shock fronts. Anomalously low volumes achieved by sandstone shocked to above approximately $40 \mathrm{~kb}$, and high calculated shock temperatures, suggest partial conversion to coesite or stishovite. High-pressure states observed in basalt and plagioclase agree with previously reported states for gabbro [Hughes and McQueen, 1958] above $300 \mathrm{~kb}$ when both data are plotted in terms of relative volume. The previously observed slope-change of the gabbro Hugoniot is believed to result from an elastic wave of perhaps $50-\mathrm{kb}$ amplitude which is overdriven at $300 \mathrm{~kb}$.
\end{abstract}

Introduction. The constitutive relation represented by the locus of shock-stress and compressed-volume states obtained in shock-wave experiments, the Hugoniot, describes material behavior over a wide pressure and temperature range. Determination of the maximum attainable longitudinal elastic-wave amplitude provides an intrinsic measurement of the strength of rocks under an extremely high (possibly maximum) loading rate. Shock-wave experimentation permits certain phenomena such as elastic-wave stress relaxation [Duvall and Fowles, 1963, p. 270] to be studied. Indirect observation of polymorphism in crustal materials appears possible in certain cases; thus interest is renewed in the study of the Hugoniots of crustal rocks, particularly as a result of the recent suggestions [Ringwood, 1962] concerning a series of reactions and phase changes occurring in the earth's mantle at a combination of pressures and temperatures higher than that obtainable in static laboratory apparatus. Additional interest stems from the application of these data to calculations describing stress-wave propagation in the vicinity of intense energy sources, such as underground explosions and meteorite impacts.
The materials here studied are polycrystalline quartz (in the form of quartzite and novaculite), sandstones of varying porosity, singlecrystal calcite, marble, porous and nonporous limestone, several plagioclases of varying composition, and a basalt. These were chosen on the basis of the following criteria: (1) extreme crustal abundance; (2) mineralogically simple rocks and chemically simple minerals; (3) materials for which reasonably uniform specimens are obtainable; and (4) mediums for which little or no previous data are reported.

Particular emphasis has been placed on studying monomineralogic mediums, since these individually display a host of new and interesting phenomena under shock compression. After these have been examined, the shock compression behavior of more complex rocks with their infinite possible variety of compositions and structures may be understood and perhaps, eventually, predicted.

\section{Symbols.}

$A$, two-dimensional wedge angle.

$a$, constant in specific heat-temperture equation.

displacement of grid image due 
to tilting of free surface by $n$th shock.

$b, \quad$ constant in specific heat-temperature equation.

$C_{0}$,

$C_{v}, C_{p}$,

$c$,

$D$

$d$ zero-pressure bulk sound speed. specific heat at constant volume, constant pressure.

constant in specific heat-temperature equation.

explosive slab detonation velocity.

initial specimen thickness, grid light source to mirror distance.

$E, E_{0}, E_{1}, E_{2}$, specific internal energy. (Unless otherwise noted, subscripts 0 , 1,2 , and $n$ refer to the initial state, and first, second, and $n$th shock front.)

$E_{k}^{q}, E_{k}^{q}$,

$E_{t}, E_{k}$,

$\Delta E^{0}{ }_{208}$

$\Delta F^{0289}$

$\Delta H^{0}{ }^{098}$,

$m$,

$P, P_{t}$

$q$

$r$,

$S, \Delta S_{288}^{0}$,

$S$,

$\mathbf{S}_{n}$,

$T, T_{0}$,

$T_{h}, T_{h}^{\prime}$,

$t_{0}, t_{1}, t_{2}, t_{n}$ compressional shock energy of quartz, stishovite.

thermal, compressional component specific internal energy.

change in standard internal energy.

change in standard free energy. change in standard enthalpy.

streak camera magnification (distance on film/distance on shot).

thermodynamic, thermal pressure.

mass fraction of quartz in quartzstishovite mixture.

radius of spherical particles.

entropy, change in standard entropy.

particle velocity coefficient of bulk sound speed.

flow along streamline at interaction of oblique shock with free surface.

temperature, temperature at zero-pressure.

Hugoniot temperature, approximate Hugoniot temperature.

shock-wave arrival time at free surface of specimen.

$U, U_{0}, U_{1}, U_{2}$, shock velocity, laboratory coordi-

$U_{\sigma}, U_{n}$,
$U_{n, \text { epp }}$

$\mathrm{U}_{n, \mathrm{app}}$,

$\Delta \mathbf{u}_{n}$, nates.

intersection velocity of $n$th shock front with inclined surface as observed by streak camera.

change in particle velocity in- $u, u_{0}, u_{1}, u_{2}$ $u_{\Lambda}, u_{n}$,

$u_{f}$,

$V, V_{0}, V_{1}, V_{2}$,

$V_{e}$,

$V_{Q}, V_{s}$

$V$,

$V_{q}, V_{\text {os }}$

$W$,

$a$,

$a_{n}$,

$\Delta a_{n}$,

$\Delta a_{n}^{\prime}$,

$b$,

$\Gamma, \Gamma_{0}$,

8

$\delta_{n}$,

$\theta_{n}^{\prime}, \theta^{\prime}$,

$\gamma_{n}^{\prime} \gamma^{\prime} ; \gamma_{n}, \gamma$,

$\theta_{n}$,

$\lambda$, duced by interaction of oblique shock with free surface.

mass (particle) velocity, laboratory coordinates.

free-surface velocity.

specific volume.

specific volume at Hugoniot elastic limit.

specific volume of quartz, stishovite.

specific shock volume required to prevent the formation of an elastic shock wave.

zero-pressure specific volume of quartz, stishovite.

streak camera writing rate (film distance/time).

foil bending angle.

inclination of wedge surface before arrival of $n$th shock front.

turning angle of wedge free surface upon incidence of $n$th shock.

correction to wedge angle due to shock tilt.

constant in Murnaghan equation of state.

Grüneisen's ratio $V(d P / d E)_{\text {}}$, Grüneisen's ratio at zero pressure.

actual; corrected angle of inclined mirror light-streak cutoff or, angle of streak displacements-both are measured from perpendicular to streak direction.

deviation angle of slit to streak orthogonality-negative when tending to be parallel with streak cutoff.

difference in angle between apparent velocity $\mathbf{U}_{n \text {, app }}$ and flow streamline $\mathbf{S}_{n}$ in flow diagram of oblique shock-free surface interaction.

shock tilt angle as measured on film-positive when oriented in direction of parallelism to streak cutoff.

shock tilt angle in specimen.

Lamé elastic constant. 
$\mu, \quad$ Lamé elastic constant (rigidity modulus).

$v, \quad$ Poisson's ratio.

$\xi$, constant in Murnaghan equation of state.

$\rho_{0}, \rho_{n}, \quad$ zero-pressure density, density associated with $n$th shock.

$\sigma, \sigma_{0}, \sigma_{1}, \sigma_{2}$, compressive stress normal to shock front.

$\sigma_{e}$, compressive stress normal to shock front at Hugoniot elastic limit.

$\bar{\sigma}_{s}, \quad$ lowest shock stress for which an elastic shock wave does not form.

$\sigma, \quad$ mean principal stress.

$\tau, \quad$ specific surface energy.

$\phi ; \phi^{\prime}, \phi_{n}^{\prime}, \quad$ actual; effective angle of inclination of mirror to free surface. $\Delta \phi, \Delta \phi_{n}, \quad$ correction for shock tilt to inclined mirror angle.

$\psi, \psi_{n}, \quad$ angle of shock with respect to detonation direction.

$\Omega, \quad$ surface energy per unit mass.

General considerations. Experimental and theoretical aspects of shock compression are described by Rice et al. [1958] and Duvall and Fowles [1963]. Aspects of shock propagation specifically applicable to geologic materials are discussed by Duvall [1962]. The stress-volume states, $\sigma-V$, achieved upon shocking a series of specimens from an initial state, $\sigma_{0}, V_{0}$, to a series of final compressed states define a curve formed by a locus of such points; this is the Hugoniot. Derived originally for fluids but valid also for solids when one-dimensional stress, $\sigma$, normal to wave front, is substituted for pressure, the Rankine-Hugoniot conservation conditions

$$
\begin{gathered}
\frac{V_{1}}{V_{0}}=1-\frac{u_{1}-u_{0}}{U_{1}-u_{0}} \\
\sigma_{1}-\sigma_{0}=\left(U_{1}-u_{0}\right)\left(u_{1}-u_{0}\right) / V_{0} \\
E_{1}-E_{0}=\frac{\sigma_{1}+\sigma_{0}}{2}\left(V_{0}-V_{1}\right)
\end{gathered}
$$

express the conservation of mass (1), momentum (2), and energy (3) across a boundary (the shock front) between the two states.

In rocks, one or more stress ranges generally exist along the Hugoniot for which states are achievable only via a multiwave shock front; that is, one or more intermediate shock states are produced which travel at discrete velocity. For example, an instability will occur in a single shock of strength $\sigma_{2}$ when it is driven into a material with a Hugoniot as represented in Figure 1. Compression to $V_{2}$ is produced via two shock fronts; the first connects state $\sigma_{0}, V_{0}$ to $\sigma_{1}$, $V_{1}$ and propagates with velocity (with respect to state $\sigma_{1}, V_{1}$ )

$U_{1}-u_{1}=V_{1}\left[\left(\sigma_{1}-\sigma_{0}\right)\left(V_{0}-V_{1}\right)^{-1}\right]^{1 / 2}$

The second connects state $\sigma_{1}, V_{1}$ to $\sigma_{2}, V_{2}$ and travels with a lower velocity

$U_{2}=-u_{1} V_{1}\left[\left(\sigma_{2}-\sigma_{1}\right)\left(V_{1}-V_{2}\right)^{-1}\right]^{1 / 2}$

also relative to $\sigma_{1}, V_{1}$. The condition for instability giving rise to such a two-wave shock may be expressed as

$$
\begin{aligned}
\left(\sigma_{1}-\sigma_{0}\right) /\left(V_{0}\right. & \left.-V_{1}\right) \\
& >\left(\sigma_{2}-\sigma_{1}\right) /\left(V_{1}-V_{2}\right)
\end{aligned}
$$

According to (6), if the straight line drawn from the initial state to the final state (the Rayleigh line) lies below intermediate points on the Hugoniot, two or more shock fronts will connect the initial and final states.

The present range of shock stresses is such that a multiwave shock front is always observable when the shock stress exceeds a stress value, $\sigma_{e}$, at the Hugoniot elastic limit (abbreviated hereafter as HEL). According to present hypotheses [Duvall and Fowles, 1963; Rice et

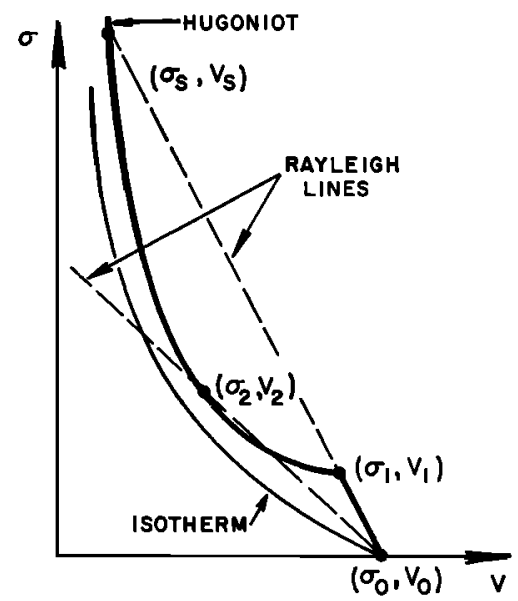

Fig. 1. Hugoniot curve which gives rise to two shock fronts between stresses $\sigma_{1}$ and $\sigma_{\text {. }}$. 
al., 1958], $\sigma_{e}, V_{e}$ is the highest shock state achievable via one-dimensional deformation in which no internal rearrangement takes place at the shock front. The experimentally observed modulus for one-dimensional shock compression for stresses below $\sigma_{e}$ in most cases corresponds closely to $\lambda+2 \mu$, indicating that the curvature of the Hugoniot is not too great; i.e., $\left(\partial^{2} \sigma / \partial V^{2}\right)$ $\left.\right|_{\sigma<\sigma_{e}} \approx 0$.

In Figure 1, state $\sigma_{1}, V_{1}$ can be considered as representing the HEL. Shock stresses immediately above $\sigma_{1}$ are achieved via a slower (relative to laboratory coordinates) plastic wave traveling at a velocity $U_{2}$, given by (5). The words 'pressure' and 'stress' are used separately to avoid any implication that the rheological behavior of the material shocked to states above the HEL is understood. In the case of nonmetallic mediums (e.g. [Duvall, 1962]) and particularly in the present study, several phenomena may be exhibited by the shocked material which are not easily explainable in terms of either ideal fluid or simple elastic-plastic behavior.

In general, the Rayleigh line passing through the HEL will again intersect the Hugoniot curve at $\sigma_{s}, V$, (Figure 1). For shocks where the final state lies between $\sigma_{e}$ and $\sigma_{s}$, a twowave shock front will exist in which the first wave corresponds to the HEL. At $\sigma_{s}$, the inequality of (6) no longer holds, and for final shock states above $\sigma$, a single shock front is stable.

A phase transition can produce a Hugoniot as

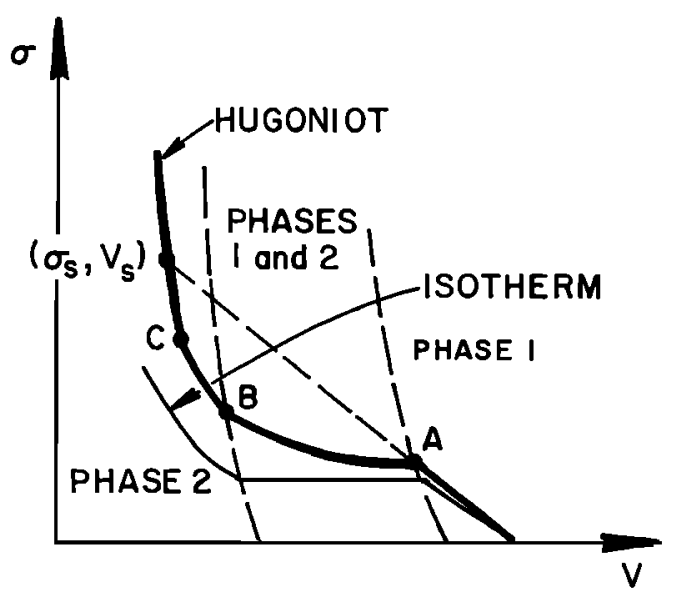

Fig. 2. Hugoniot curve for material with exothermic phase transition. in Figure 2 (exothermic) where a multiwave shock may exist over a certain stress range due to the cusp at $A$. As in the case of the HEL, the stability of more than one shock front is predicted by (6). The cusp at $B$ does not, in general, produce a multiple shock; the Hugoniot in this region is obtained from a series of experiments where successively stronger shocks trace out states along $A B C$. Since two quantities, shock and particle velocity, associated with each state of a multiwave shock front are usually measured, there is, in principle, no method of distinguishing the HEL phenomenon from polymorphism by using shock compression data alone. Even when elastic-wave velocities, and supplementary phase equilibrium and thermodynamic data, become available (e.g., in calcite rocks, described below), interpretation of observed transition points on the Hugoniot may be difficult.

Experimental techniques. The experimental techniques described are designed to measure shock velocity $U_{x}$ and particle velocity $u_{1}$, in order to calculate stress $\sigma_{1}$, volume $V_{1}$, and change in specific internal energy $E_{1}-\mathrm{E}_{0}$, by using (1), (2), and (3). Quantities which refer to an initial state in (1), (2), and (3) are assumed to be known because they refer either to the uncompressed state or to the state achieved via a previous shock front, in which case they have been calculated.

The three optical techniques described were developed for shock measurements in metals; the description emphasizes aspects which apply uniquely to brittle materials.

Plane-wave inclined-mirror method. The Hugoniot for any of the mediums studied may be represented, at least in a limited stress range, by a curve in the stress-particle velocity plane such as OAB (Figure 3). In discussing experimental technique it is useful to consider loci of unloading states achieved by shocked material driven to state $B$ via state $A$. For isentropic processes the loci of unloading states also correspond to the thermodynamic paths. State $A$ may correspond to either a HEL or to the onset of a polymorphic transition. The shock velocity corresponding to compression from $O$ to $A$ is directly obtained from $U_{1}=d /\left(t_{1}-t_{0}\right)$ to within $\pm 1 \%$.

The particle velocity associated with state $A$, $u_{1}$, is obtained by measuring the free-surface 


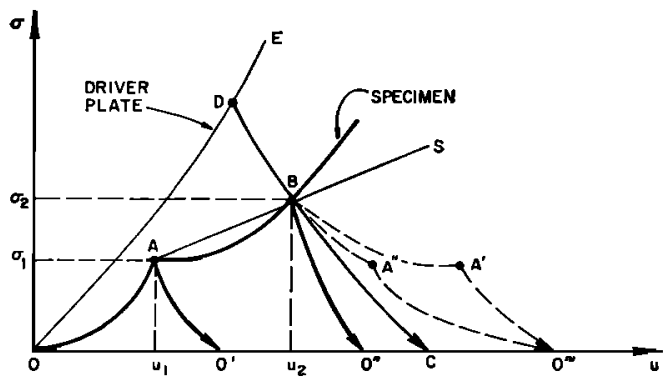

Fig. 3. Stress-particle velocity curve for typical rock. $O, A$, and $B$ are achieveable states on rock Hugoniot; free-surface velocities indicated at $O^{\prime}$, $O^{\prime \prime}$, and $O^{\prime \prime \prime}$ for rock, at $C$ for driver plate.

velocity indicated by $O^{\prime}$ and assuming that this is equal to twice the particle velocity. Thus the locus of unloading states $A O^{\prime}$ is assumed to be the mirror image of the loading curve $O A$. This approximation is valid if no irreversible structural changes occur and if the entropy increase from $O$ to $A$ is small [Rice et al., 1958]. This seems to be the case, since the shock velocities associated with the stress level of either the HEL or the wave corresponding to the lowestpressure transition state is often within a few per cent of the adiabatic longitudinal-wave velocity. For this reason the free-surface approximation appears to be valid even for porous rocks up to and including the HEL.

Velocities imparted to the free surface of the specimen by the arrival of each shock front are obtained (appendix A) by measuring the appropriate light-streak cutoff angle $\gamma^{\prime}$.

The velocity of the second shock front corresponding to state $B$ is approximately

$$
U_{2}=\frac{d+2\left(t_{2}-t_{1}\right) u_{1}}{t_{2}-t_{0}}
$$

Here the interaction of the reflected wave represented by state $A$ with the oncoming shock (state $B$ ) is neglected. In general, assuming no wave interactions, the shock velocity of the $n$th front is

$$
U_{n}=\frac{d+2 \sum_{k=2}^{n} \int_{t_{k-1}}^{t_{t}} u_{k-1} d t}{t_{n}-t_{0}}
$$

The interaction of reflected waves (rarefactions) with later shocks propagating toward the free surface of the specimen may be taken into ac- count by assuming a particular model for material behavior in the shocked state. In practice it may be difficult to demonstrate the uniqueness of a particular model. Also, because of the general agreement in the resulting final states found by using two different methods, wave interactions are not considered in the initial data analysis.

The particle velocity, $u_{2}$, associated with the state $B$, the highest stress state achieved in the hypothetical experiment of Figure 3, may be obtained by taking one-half of the free-surface velocity indicated at $O^{\prime \prime \prime}$ in either of the following cases: (1) state $A$ must represent a polymorphic transition which is readily reversible in times comparable to the duration of state $A$ (about $0.1 \mu \mathrm{sec}$ ) (this implies unloading of stress in the material along the path $B A^{\prime} O^{\prime \prime \prime}$, which is the approximate mirror image of the locus of compression states) or (2) state $A$ represents the HEL of a nonporous solid, in which case unloading occurs along some hypothetical path $B A^{\prime \prime} O^{\prime \prime \prime}$ which may differ in detail from the mirror image of $O A B$. The path shown in Figure 3 might be typical of an elastic-plastic solid, with relief of the elastic compression $B A^{\prime \prime}$ followed by relaxation of the plastic component $A^{\prime \prime} O^{\prime \prime \prime}$. Fortunately, the value of free-surface velocity does not appear to depend critically on details of the unloading path. Particle velocities, obtained by using the free-surface approximation in the above situations usually agree with those obtained from an impedance-match solution (discussed below).

For a porous material shocked to state $B$, where state $A$ now represents the HEL, the reduction of stress will proceed along a path $B O^{\prime \prime}$ which is characteristic of the compacted material. The free-surface velocity determined at $O^{\prime \prime}$ provides useful data, not available from the Hugoniot, as to the nature of the shocked material. An impedance-match solution [Rice et al., 1958] is used to obtain the final shock state $B$ for porous mediums with state $A$ taken as the initial state. State $D$ in the driver plate required for the impedance-match solution is obtained from the corresponding free-surface velocity indicated at point $C$ in Figure 3 . The streak cutoff from the inclined mirror mounted on the driver plate (Figure 4) determines the driver free-surface velocity and serves to 'monitor' the shock profile impinging on the specimen 


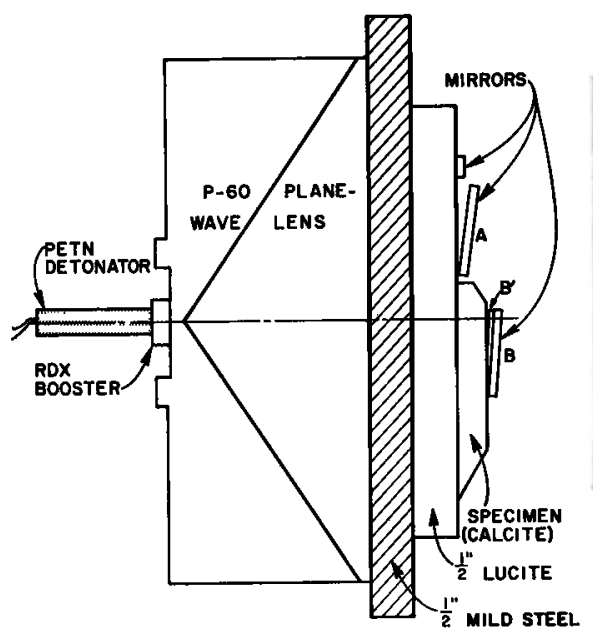

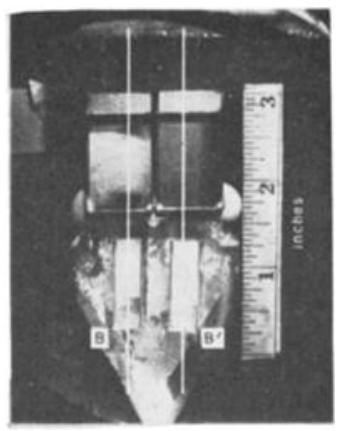

(b)

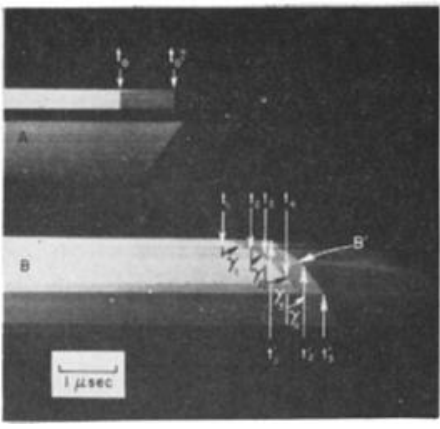

(c)

(a)

Fig. 4. Plane-wave inclined mirror assembly, shot 8853 ; $(a)$ side-view; (b) front-view, as seen by streak camera; $(c)$ streak camera record with four and three discrete free-surface velocities indicated by inclined mirror records $B$ and $B^{\prime}$, respectively.

to assure that the shock stress remains at a constant value for a time comparable to that of the shock transit through the specimen. The inclined mirror will function in this latter role only when spallation of the driver plate does not occur.

The inclined mirror and impedance-match method and the plane-wave wedge method (next section) suffer a disadvantage in that the particle velocity obtained corresponds to that in a plane at either the upper- or lower-specimen surface, whereas the shock velocity obtained corresponds to an average of the travel time through the specimen. Although the use of thick explosive pads and driver plates in the experiments can, in principle, minimize the hydrodynamic attenuation [Courant and Friedrichs, 1948, chapter 3] in a nonsteady ideal shock, attenuation resulting from dissipative mechanisms, particularly in porous rocks, must be seriously examined. For the plane-wave methods shock velocity is often measured through specimens of different thicknesses, permitting the shock velocity to be corrected to the plane of the particle velocity determination.

The experimental arrangement (Figures $4 a$ and $4 b$ ) consists of a plane-wave explosive lens and a cylindrical high-explosive pad which is placed in contact with a driver assembly. A planar shock of an amplitude characteristic of the high-explosive type [Duvall and Fowles, 1963] and, to a lesser extent, of the explosive and driver plate thickness is driven into the specimen. The cast explosive pad, uniform in density and free from visible defects, is often placed in contact with the lapped surface of one or more driver plates (not illustrated by shot in Figure 4). The Hugoniots of the driver plate mediums are usually known. The explosive pad and driver plates are flat and parallel to within $0.001 \mathrm{in}$. The explosive pad, when detonated by the plane-wave lens, induces a shock which emerges from the driver plate with a planarity of typically $\pm 0.02 \mu \mathrm{sec}$ across $75 \%$ of the explosive pad diameter. The explosive systems used to obtain the present data are summarized in Table 1.

One or more specimens with appropriate flat and inclined mirrors (Figures $4 a$ and $4 b$ ) are cemented to the upper surface of the driver plate. The lower surfaces of the mirrors (and specimens, when these are transparent) are aluminized. The upper surface of the driver plate supporting the inclined mirror(s) and specimen(s) is enclosed in a vacuum chamber and evacuated to $<0.001$ bar. The assembly is illuminated from above through a plate-glass port by an argon flash bomb. The light reflec- 
TABLE 1. Explosive Driver Systems

\begin{tabular}{|c|c|c|c|c|}
\hline Designation & $\begin{array}{c}\text { Explosive System* } \\
\text { Pad Thicknesses, } \\
\text { mm }\end{array}$ & $\begin{array}{c}\text { Driver Plates* } \\
\text { Thickness, Material, } \\
\text { mm }\end{array}$ & $\begin{array}{c}\text { Stress, } \uparrow \\
\text { kb }\end{array}$ & $\begin{array}{l}\text { Free-Surface } \\
\text { Velocity, } \dagger \\
\mathrm{mm} / \mu \mathrm{sec}\end{array}$ \\
\hline 1 & P-40† & 12.7 Plexiglas & 62 & 2.39 \\
\hline 2 & $P-40$ & 12.7 Aluminum (2024) & 127 & 1.43 \\
\hline 3 & P-60 & 12.7 Plexiglas & 65 & 2.46 \\
\hline 4 & P-60 & 25.4 Plexiglas & 58 & 2.25 \\
\hline 5 & $\mathrm{P}-60$ & 12.7 Aluminum (2024) & 121 & 1.37 \\
\hline 6 & P-60 & 12.7 Mild Steel + 12.7 Plexiglas & 29 & 1.36 \\
\hline 7 & $\mathrm{P}-60$ & 12.7 Brass + 12.7 Plexiglas & 27 & 1.44 \\
\hline 8 & $\mathrm{P}-60$ & 12.7 Brass + 19.0 Plexiglas & 22 & 1.08 \\
\hline 9 & P-60 + 25.4 Baratol & 12.7 Aluminum (2024) & 134 & 1.52 \\
\hline 10 & $\mathrm{P}-60+50.8$ Baratol & 6.4 Aluminum (2024) & 147 & 1.64 \\
\hline 11 & P-60 + 50.8 Baratol & 19.0 Aluminum (2024) & 138 & 1.54 \\
\hline 12 & P-60 + 25.4 Comp B-3 & 12.7 Aluminum (2024) & 257 & 2.61 \\
\hline 13 & P-60 + 25.4 Comp B-3 & 25.4 Aluminum (2024) & 208 & 2.21 \\
\hline 14 & P-60 + 50.8 Comp B-3 & 6.4 Aluminum (2024) & 326 & 3.14 \\
\hline 15 & P- $60+50.8$ Comp B-3 & 12.7 Aluminum (2024) & 300 & 2.95 \\
\hline 16 & P-60 + 12.7 Comp B-3 + 25.4 & 12.7 Aluminum (2024) & 182 & 1.97 \\
\hline 17 & $\mathrm{P}-80$ & 12.7 Brass + 25.4 Plexiglas & 16 & 0.84 \\
\hline
\end{tabular}

* As sequentially reached by shock (or detonation) wave.

$\dagger$ Nominal, referred to last driver-plate material listed.

¥ Refer to 4-, 6- and 8-inch-diameter plane-wave explosive lenses manufactured by Mason and Hanger, Amarillo, Texas.

ted by the mirrors is incident on one or more slits of a streak camera (writing rate of $3.8 \mathrm{~mm} /$ $\mu \mathrm{sec}$ on $35-\mathrm{mm}$ film).

The shock velocity associated with shock state $A$ (Figure 4) is obtained by measuring the time delay, $t_{1}-t_{0}$, between loss of reflectivity of the mirrored surfaces on the upper surface of the driver plate and the mirrors at the upper specimen surface. When more than one shock front is produced in the specimen, shock front arrivals at the upper specimen surface are obtained by noting the times when an increase of the impaction rate of the inclined mirror with the free surface occurs. This is illustrated by the trace of the inclined mirror of Figure 4, set initially at an angle $\phi=\approx 2^{\circ}$ to the free surface; successive arrivals of four shock fronts are indicated at times $t=t_{1}, t_{2}, t_{3}$, and $t_{4}$. The free-surface velocity associated with each shock arrival is obtained from the angle of the streak cutoff (appendix A).

Plane-wave wedge method. A wedge-shaped specimen (Figure 5), in combination with a planar explosively driven shock (Table 1), is used to observe continuously the particle velocity profile of a multiwave shock front at a series of points corresponding to a range of shock propagation path lengths. Because polished rock surfaces generally do not reflect light specularly after incidence of a fairly weak shock front, the scheme described below was devised to determine both shock front arrivals and particle velocities in the oblique geometry of the planewave wedge and the two-dimensional wedge.

Two metal plates (faces parallel to \pm 0.001 in.), polished on one side and chosen for a shock impedance greater and less than that expected in the specimen, are cemented to the upper specimen surface. The wedge angle of the specimen is of the order of $10^{\circ}$. A similarly shaped metal wedge (usually aluminum) with a polished surface is also mounted on the aluminum driver plate. Small glass mirrors mounted on the driver plate serve to monitor the incident shock planarity.

An argon light source consisting of grid lines oriented perpendicularly to the slit direction illuminates the upper surface of the specimen assembly (Figure 5). The specular reflection from the mirrored surfaces of the two metal strips and the flat glass mirrors is observed along two slits by a streak camera loaded with 


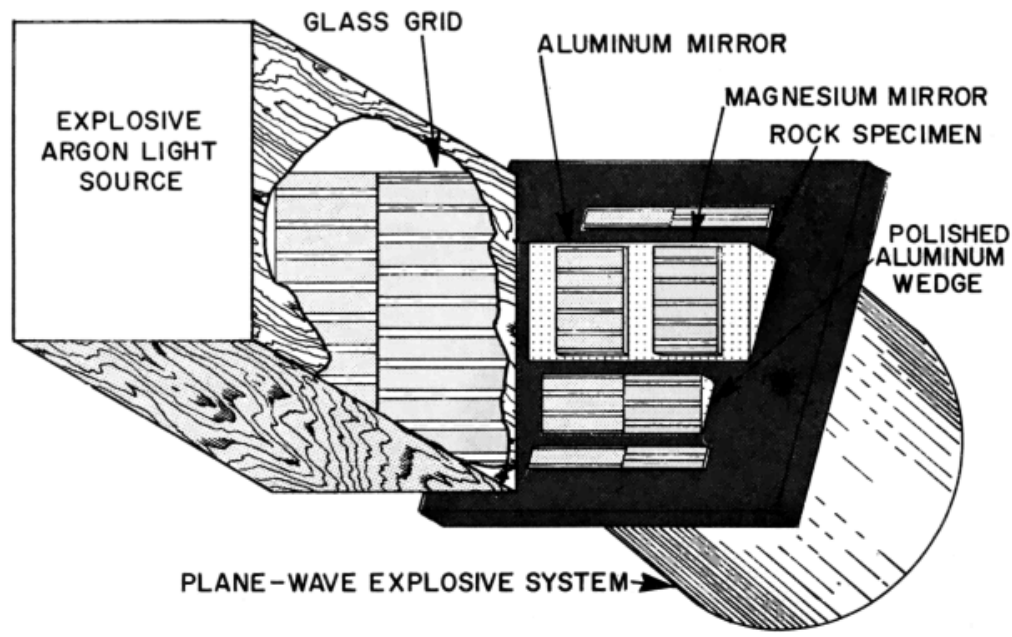

Fig. 5. Streak camera view of plane-wave wedge experiment.

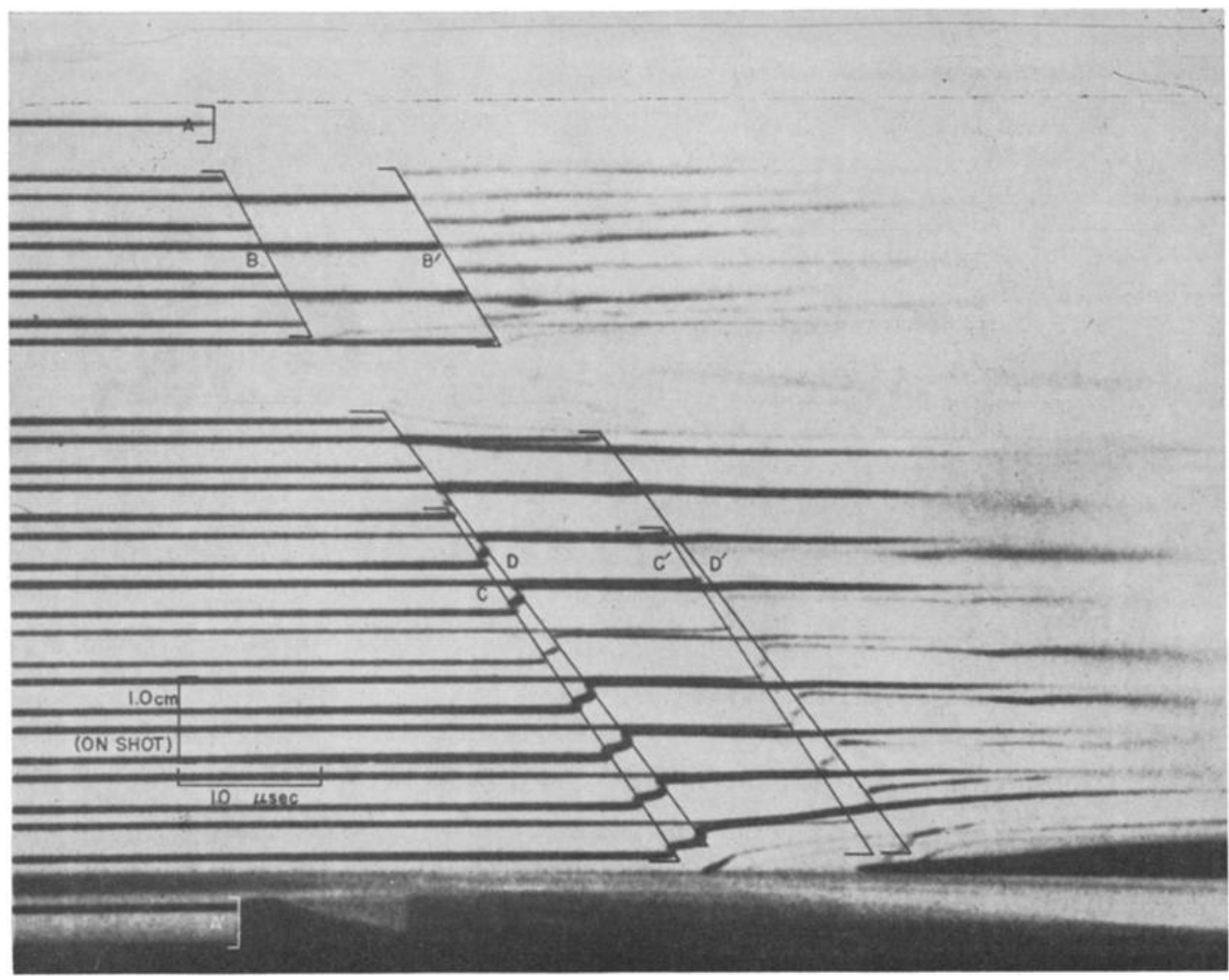

Fig. 6. Streak camera record, plane-wave wedge experiment, Sioux quartzite specimen (original on Ektachrome); $\mathbf{A}$ and $\mathbf{A}^{\prime}$, flat mirrors on driver plate; $\mathbf{B}$ and $\mathbf{B}^{\prime}$, streak displacements from shock in aluminum wedge; $\mathbf{C}$ and $\mathbf{C}^{\prime}$, elastic wave in aluminum and magnesium mirrors, respectively; $D$ and $D^{\prime}$, final state in aluminum and magnesium mirrors, respectively. 
a high-speed color film. The grid lines observed with one slit are offset from those of the other slit. Transmission filters over each slit color the traces differently (a refinement devised by D. R. Grine) and further minimize streak interference in the resulting double exposure (Figure 6).

The inclined-wedge surface is adjusted so as to be perpendicular to the axis of the streak camera. As a succession of $n$ possible plane shock fronts impinge on the wedge surface, they intersect the inclined surface with an apparent velocity given by

$$
U_{n, \mathrm{app}}=W / \tan \gamma_{n}{ }^{\prime}
$$

as seen by the streak camera. (See details in appendix B.) Here $W$ is the streak camera writing rate and $\gamma_{n}^{\prime}$ the angle which the streak displacements make with the normal to the streak direction. The angle $\gamma_{n}^{\prime}$ is corrected for nonorthogonality of slit to streak direction. The velocity of the $n$th shock front in the rock is

$$
U_{n}=U_{n, \mathrm{app}}\left(\sin \alpha_{n}\right) / m
$$

where the wedge angle $\alpha_{n}$ is decreased slightly (by $\Delta \alpha_{n-1}$ ) from incidence of each previous $(n-1)$ th shock front. The wedge angle $\alpha_{n}$ is corrected for planar shock tilt, detected by observing the degree of nonsimultaneity of the light cutoff from flat mirrors such as $A$ and $A^{\prime}$ of Figure 6 . The tilt correction applied to $\alpha_{n}$ is (assuming refraction of the shock at the driver plate-specimen interface)

$$
\Delta \alpha_{n}{ }^{\prime}=U_{n} \frac{m}{W} \theta_{n}{ }^{\prime}
$$

$U_{n}$ is generally obtained from (10), with $\alpha_{n}$ uncorrected; then $\alpha_{n}$ is corrected using (11), and $U_{n}$ is recomputed. The correction is usually small, and further iteration is unnecessary.

The shock velocities in the rock obtained from the angle of the streak displacement in the metal mirrors are accurately determined only when the shock velocity in the metal mirror remains nearly constant along the section observed by the slit.

Deviations from shock planarity (of the order of $\pm 0.015 \mu \mathrm{sec}$ at the upper surface of the driver plate) do not generally permit observation of significant variations in shock velocity for the different rock thicknesses observed along the slit. Variations in particle velocity, however, are much greater for comparable changes in shock pressure. The plane-wave wedge method permits observation of these for a series of thicknesses corresponding to the position of each light streak.

Although the velocity of the $n$th shock front in the rock is obtained from the angle of the streak displacement $\gamma_{n}^{\prime}$, the rock's particle velocity must be inferred from observation of the corresponding stress versus particle velocity state in each of the metal mirrors. The particle velocities of the metal mirrors are determined by measuring streak displacements produced upon arrival of each shock front. The analysis is described in appendix $B$.

The known Hugoniots of the metal mirrors, usually aluminum and magnesium (Figure 5), when plotted in the stress-particle velocity plane (Figure 7), lie on either side of the corresponding specimen curve (initially unknown). The metal mirrors are sufficiently thick so that the time interval between the arrival of the initial and final shock states at the mirror freesurface is less than the mirror reverberation time (twice mirror thickness/mirror shock velocity). Hence each shock front in the rock is transmitted into the metal mirror and is allowed to interact with the mirror free-surface (imparting a characteristic free-surface velocity) before the arrival of interactions reflected from the rock-metal interface. The free-surface approximation is used to obtain particle velocities corresponding to different states in the mirrors. In Figure 7, free-surface velocities $O^{\prime}$ and $O^{\prime \prime}$ determine states $B$ and $D$ on the known $\sigma$ versus

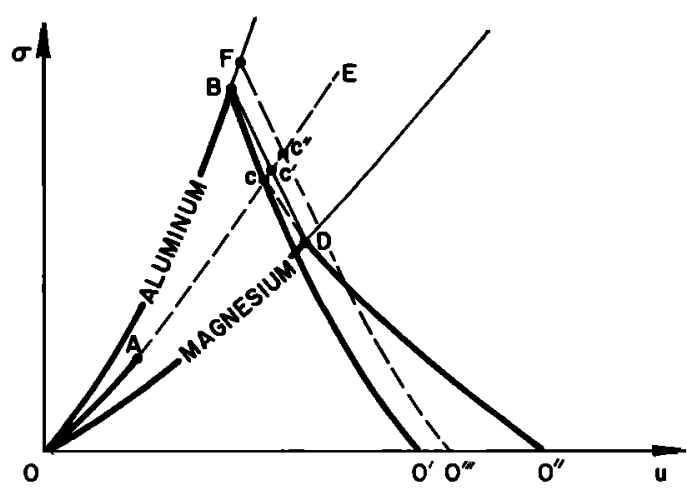

Fig. 7. Stress-particle curves for determining specimen state $C$ from states $B$ and $D$ observed in metal mirror. 
$u$ curves for aluminum and magnesium, respectively. States $B$ and $D$ must lie on the locus of states achievable by wave reflections from the unknown state $C$ in the specimen. The locus of wave-reflection states is approximated over a short distance by line $B D$. From knowledge of the previous state (which is either at zero stress or at $A$ as shown, the latter due to a HEL or phase transition) and of the measured shock velocity appropriate to the state $C$, the line $A E$ of slope $\rho_{A}\left(U_{o}-u_{A}\right)$ is constructed on the basis of (2). Subscripts $A$ and $C$ refer to states shown in Figure 7. Since the state in the specimen is known to lie on $A E$ and also along the curve approximated by line $B D$, the intersection point, $C^{\prime}$, is assumed to closely approximate the desired state $C$. Point $C^{\prime}$ will always lie above the actual state $C$, since $\sigma-u$ curves are convex downward.

A check on the determination of state $C^{\prime}$, providing an upper limit to the true value (because of shock attenuation in the specimen), is available from knowledge of the final shock state in the driver plate obtained from streak deflections from a wedge of material (usually aluminum) identical to the driver plate (Figures 5 and 6). For a free-surface velocity $O^{\prime \prime \prime}$ corresponding to a state $F$ in the driver (Figure 7), a state $C^{\prime \prime}$ is obtained in the specimen from the impedance-match method.

Two-dimensional wedge method. The twodimensional wedge technique [Katz et al., 1959; Fowles, 1961a], although more difficult to perform and analyze than the methods already described, is advantageous because it yields Hugoniot data over a stress range in one experiment. It is especially useful at lower stress levels that are troublesome to achieve in plane geometry with explosive systems. A detonation front of constant velocity $D$ propagates in an explosive slab in contact with a bar-shaped specimen. This produces within the specimen a curved shock front resulting from shock attenuation. When the detonation and accompanying oblique shock front have traveled far enough, a steady shock configuration will exist in the specimen; i.e., the point of intersection of the shock with any line $O O^{\prime}$ (Figure 8) will travel with the detonation velocity. As in the plane-wave wedge method two metal mirrors are cemented on the wedge surface. These detect both the intersection velocity $U_{n \text {, app }}$ and mirror deflection $\Delta \alpha_{n}$ induced by each of the $n$ shocks produced in the specimen.

The analysis required to obtain Hugoniot data for the two-dimensional wedge is similar to that for the plane-wave experiment; the main difference is that shock velocity, in addition to particle velocity, can be observed to vary signifcantly along the wedge face. The shock-wave velocity at a given distance from the explosive is related to the detonation velocity and $U_{n \text {, app }}$

$$
U_{n}=D \sin \psi_{n}=U_{n, \mathrm{avD}}\left(\sin \alpha_{n}\right) / m
$$

and

$$
A=\psi_{n}+\alpha_{n}
$$

It follows from (12) and (13) that

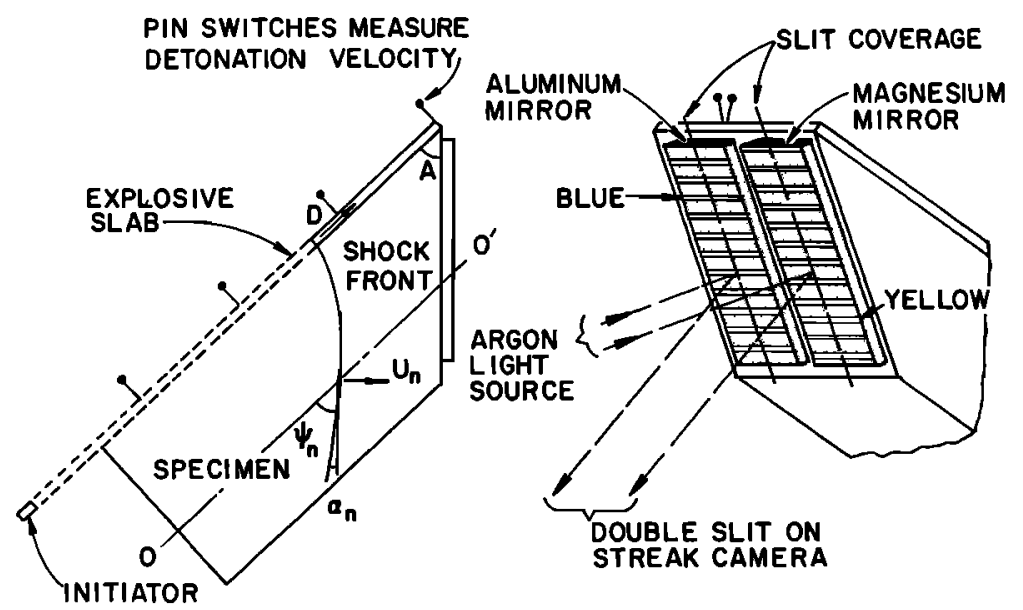

Fig. 8. Experimental assembly, two-dimensional wedge method. 


$$
\cot \psi_{n}=\cot A \pm \frac{m D}{U_{n, \mathrm{aDD}} \sin A}
$$

where the (+) is for $\psi_{n}<A$ and the (-) is for $\psi_{n}>A$. Since $D$ is known from electronic pin switch measurement and $U_{n \text {, app }}$ is observed in the streak camera film, $\psi_{n}$ and hence $U_{n}$ may be obtained at different positions on the wedge face. The particle velocities $u_{n}$ in the metal mirrors corresponding to shock fronts in the specimen are obtained from displacements of streaks corresponding to different positions on the wedge face as in the plane-wave wedge method (appendix B).

The rapid variation in shock states with distance along the wedge face unfortunately disallows strict correlation between adjacent streaks in the two mirrors that are almost equidistant from the explosive slab. The state in the rock corresponding to each observed state in a mirror is obtained from the intersection of the line of slope $\left(U_{n}-u_{n-1}\right) \rho_{n-1}$ drawn from the previous $(n-1)$ th state (e.g., $O^{\prime} A^{\prime}$, Figure 9), with a line of slope $\left(u_{n-1}-U_{n}\right) \rho_{n-1}$ (e.g., $A A^{\prime}$, Figure 9) drawn from the state observed in the mirror. Although this method is necessarily approximate, for rocks where wave reflection curves are nearly identical to the mirror images of shock compression curves in the stress-particle velocity plane, the Hugoniots obtained from the different metal mirrors are consistent both with each other and with those from the other methods. The present experience suggests from comparison with data obtained using other

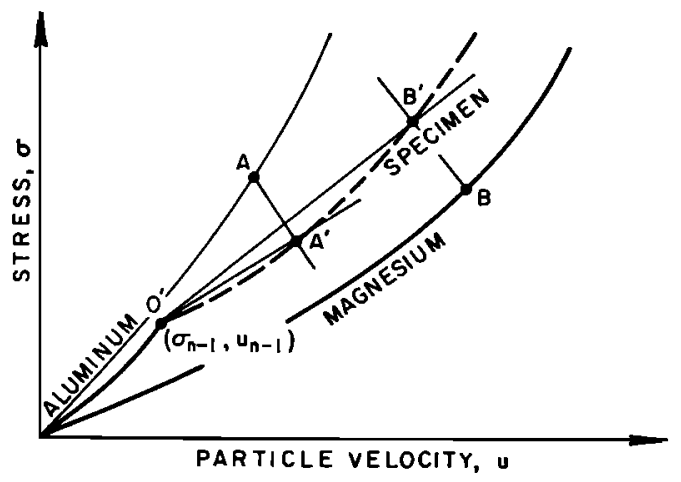

Fig. 9. Graphical solution for unknown Hugoniot points $A^{\prime}$ and $B^{\prime}$ (separation exaggerated) using observed mirror states $A$ and $B$ and mirror image approximation of slope $\left(U_{n}-u_{n-1}\right) \rho_{n-1}$. methods that the above approximation is generally invalid for porous rocks.

Specimen preparation. Rock and mineral specimens (Table 2) in both plane and oblique configurations are sawed (diamond-blade) and surface-ground to appropriate sizes. Rectangular specimens are ground to a thickness tolerance (in the plane of the shock) of $\pm 0.005 \mathrm{~mm}$ and $\pm 0.025 \mathrm{~mm}$ for nonporous and porous rocks, respectively. Specimens for both planewave wedge and inclined-mirror techniques are typically $6 \mathrm{~mm}$ thick and $40 \mathrm{~mm}$ square. Rock bars for two-dimensional wedge experiments are typically $5 \times 12 \times 25 \mathrm{~cm}$. Specimen initial densities are obtained from measurement of dimensions and mass for specimens without obvious flaws. Otherwise, larger cuboids (approximately $250 \mathrm{~cm}^{3}$ ) are specially fabricated to determine initial density.

Initial optical orientation of calcite specimens permits sawing and preliminary lapping. $\mathrm{Ob}$ servation of cut surfaces with a series of Laue back-reflection photographs permits final orientation and lapping of surfaces. These are perpendicular to the $x, y$, and $z$ direction to within $\pm 1^{\circ}$. The $[10 \overline{1} 1]$ specimens are oriented using cleavage planes.

Rock specimens are cut in random orientation, except that difficulties in surface preparation dictate that sandstone be cut on a plane parallel to the bedding plane. Thin sections of typical Arkansas novaculite and Spergen limestone displayed no distinct $c$-axis alignment. Thin sections of Yule marble cut from one of the specimens showed that $22 \%$ of the calcite $c$ axes lay in a single cone of 0.11 steradian. In typical Coconino sandstone samples, the quartz $c$ axes were found to be aligned so that $29 \%$ lay within two cones totaling 0.24 steradian and oriented approximately $30^{\circ}$ from the bedding plane. In Eureka quartzite, the quartz $c$ axes were found to be bimodally distributed so that $28 \%$ of the grain $c$ axes were oriented in a total cone of 0.23 steradian. We did not attempt to detect anisotropy in other rocks by microscopic examination.

Quartz and quartzites. The Hugoniot for various cuts of single-crystal quartz has been obtained independently by Wackerle [1962] and Fowles [1961b], and it demonstrates reproducibility within the accuracy of experiments. The Hugoniots for Arkansas novaculite 


\begin{tabular}{|c|c|c|c|}
\hline Material; Source & $\begin{array}{l}\text { Mineralogic Composition, } \\
\text { Grain Size, Cement }\end{array}$ & $\begin{array}{l}\text { Nominal } \\
\text { Density, } \\
\text { g/cm }\end{array}$ & $\begin{array}{l}\text { Nominal } \\
\text { Porosity, } \\
\quad \%\end{array}$ \\
\hline $\begin{array}{l}\text { Arkansas novaculite; Behr-Manning } \\
\text { Co., Troy, New York }\end{array}$ & $\begin{array}{l}\sim 100 \% \text { quartz grains, random orienta- } \\
\text { tion, intensely interlocked, } \sim 0.01 \mathrm{~mm} \\
\text { diam. }\end{array}$ & 2.65 & \\
\hline $\begin{array}{l}\text { Sioux quartzite; quarry of L. G. } \\
\text { Everist, Inc., Dell Rapids, S. Dak. }\end{array}$ & $\begin{array}{l}\text { 99\% quartz grains with overgrowths } \\
0.1 \text { mm diam.; hematite dust; silica } \\
\text { cement }\end{array}$ & 2.64 & $<1$ \\
\hline $\begin{array}{l}\text { Eureka quartzite; Confusion Mountain, } \\
\text { near Ely, Nev. [U] }\end{array}$ & $\begin{array}{l}\text { } 99 \% \text { quartz, interlocking grains, minor } \\
\text { silica cementation }\end{array}$ & 2.58 & $<1$ \\
\hline St. Peter sandstone; Klondike, Mo. [W] & $\sim 99 \%$ quartz, $0.05-0.4 \mathrm{~mm}$ diam. & 2.14 & 20 \\
\hline $\begin{array}{l}\text { Massillon sandstone; quarry of Briar } \\
\text { Hill Stone Co., Glenmont, O. }\end{array}$ & $\begin{array}{l}94 \% \text { quartz, } 0.01-0.5 \mathrm{~mm} \text { diam.; } 6 \% \\
\text { feldepar, hematite, and clay }\end{array}$ & 1.99 & 24 \\
\hline $\begin{array}{l}\text { Coconino sandstone; Flagstaff, Ariz. } \\
{[\mathrm{U}]}\end{array}$ & $\begin{array}{l}97 \% \text { quartz; } 3 \% \text { orthoclase, } 0.1-0.2 \mathrm{~mm} \\
\text { diam.; weak silica cement }\end{array}$ & 1.99 & 24 \\
\hline $\begin{array}{l}\text { Calcite (Iceland Spar), Chihuahua, } \\
\text { Mexico; Scott Williams Mineral Co., } \\
\text { Scottsdale, Ariz. }\end{array}$ & $\begin{array}{l}\text { Single crystal, colorless, no visible } \\
\text { defects }\end{array}$ & 2.71 & \\
\hline Yule marble; Gunnison City, Colo. [U] & $\begin{array}{l}\sim 100 \% \text { platy calcite grains, } 0.2-0.4 \mathrm{~mm} \\
\text { diam.; pronounced c-axis orientation }\end{array}$ & 2.70 & $<1$ \\
\hline $\begin{array}{l}\text { Vermont marble; West Rutland, Vt. } \\
{[\mathrm{W}]}\end{array}$ & $\begin{array}{l}\sim 95 \% \text { calcite, } 0.05-0.2 \mathrm{~mm} \text { diam.; } 5 \% \\
\text { secondary quartz }\end{array}$ & 2.69 & \\
\hline $\begin{array}{l}\text { Solenhofen limestone; Solenhofen, } \\
\text { Bavaria }[\mathrm{W}]\end{array}$ & $\begin{array}{l}\text { 96\% calcite, } 0.005-0.015 \mathrm{~mm} \text { diam.; } \\
\text { balance clay and quartz }\end{array}$ & 2.58 & $\sim 1$ \\
\hline $\begin{array}{l}\text { Spergen limestone; quarry of Indiana } \\
\text { Limestone Co., Bedford, Ind. }\end{array}$ & $\begin{array}{l}\text { 100\% calcite, } 0.1-0.7 \mathrm{~mm} \text { diam.; } 60 \% \\
\text { fossil fragments, calcite matrix }\end{array}$ & 2.38 & 12 \\
\hline $\begin{array}{l}\text { Anorthosite; Aqua Dulce quad., Calif. } \\
\text { NE } 1 / 4 \text { of } S W 1 / 4, S .14, T 4 N \text {, } \\
\text { R14W }\end{array}$ & $\begin{array}{l}98 \% \text { andesine, } 1-8 \mathrm{~mm} \text { diam.; also } \\
\text { imbedded apatite, zircon, chlorite, } \\
\text { horneblende and biotite, } 0.01-0.03 \mathrm{~mm} \\
\text { diam. }\end{array}$ & 2.66 & \\
\hline Labradorite; Labrador, Canada [W] & $\begin{array}{l}\text { Single crystal, with 1-cm domains, poly- } \\
\text { synthetic twins } \sim 1 \mathrm{~mm} \text { apart }\end{array}$ & 2.69 & \\
\hline Albite; Ontario, Canada [W] & $\begin{array}{l}\text { Single crystal, with parallel } 2 \mathrm{~cm} \text {, minor } \\
\text { misorientation, some Carlsbad twins }\end{array}$ & 2.58 & \\
\hline $\begin{array}{l}\text { Vacaville basalt; Mt. Vaca quad., Calif., } \\
\text { NE } 1 / 4 \text { of } \mathrm{S} .23, \mathrm{~T} 7 \mathrm{~N}, \mathrm{R} 2 \mathrm{~W} \text { [U] }\end{array}$ & $\begin{array}{l}53 \% \text { andesine [An45-An53]; } 31 \% \text { augite; } \\
9 \% \text { magnetite-ilmenite; } 5 \% \text { celadonite } \\
\text { and } 2 \% \text { apatite; grains } 0.02-0.2 \mathrm{~mm} \\
\text { diam.; Type } 2312 \mathrm{E} \text {, [Johannsen, } 1939 \text { ] }\end{array}$ & 2.82 & $\begin{array}{l}3 \text { (due to } \\
\text { vesicles) }\end{array}$ \\
\hline
\end{tabular}

[U] Obtained courtesy of U. S. Geological Survey, Menlo Park, Calif.

[W] Purchased from Wards Natural Science Establishment, Inc., Rochester, N. Y.

and Sioux and Eureka quartzite (Table 3) are in general agreement with Wackerle's data for crystal quartz (Figure 10).

For different cuts of quartz, it is not clear how Hugoniot data are best represented in the stress-volume or stress-particle velocity plane so that they may be compared with those for polycrystalline quartz. Wackerle has calculated the shock and particle velocities in quartz that are appropriate to hypothetical shock transitions directly from zero stress to shock states normally achieved only by means of a two-wave 
TABLE 3. Hugoniot I)ata, Solid Quartz Rocks

\begin{tabular}{|c|c|c|c|c|}
\hline $\begin{array}{l}\text { Specimen Type; } \\
\text { Initial Density, } \\
\mathbf{g} / \mathrm{cm}^{3}\end{array}$ & $\begin{array}{c}\text { Experimental Arrangement; } \\
\text { Explosive Driver System; } \\
\text { Driver Free-Surface Velocity, } \\
\mathrm{mm} / \mu \mathrm{sec}\end{array}$ & $\begin{array}{l}\text { Shock } \\
\text { Velocity, } \\
\mathrm{mm} / \mu \mathrm{sec}\end{array}$ & $\begin{array}{l}\text { Particle } \\
\text { Velocity, } \\
\mathrm{mm} / \mu \mathrm{sec}\end{array}$ & $\begin{array}{l}\text { SRI } \\
\text { Shot } \\
\text { No. }\end{array}$ \\
\hline Arkansas novaculite; 2.65 & $A \& B ; 5 ; 1.188$ & $\begin{array}{l}588 \dagger \\
3.12\end{array}$ & $\begin{array}{l}0.53 \dagger \\
0.66\end{array}$ & 8238 \\
\hline Arkansas novaculite; 2.65 & $\mathrm{~A} ; 5$ & $\begin{array}{l}6.40 \dagger \\
3.87\end{array}$ & $\begin{array}{l}0.571 \dagger \\
0.94\end{array}$ & 8270 \\
\hline Arkansas novaculite; 2.642 & $\begin{array}{l}\text { C; } 6.4 \mathrm{~mm} \text { Comp B-3 in contact } \\
\text { with specimen }\end{array}$ & $\begin{array}{l}6.235 \\
6.225 \\
6.190 \\
6.129\end{array}$ & $\begin{array}{l}0.479 \\
0.449 \\
0.386 \\
0.135\end{array}$ & 8300 \\
\hline Arkansas novaculite; 2.649 & $\begin{array}{l}\text { C; } 6.6 \mathrm{~mm} \text { EL-506D in contact } \\
\text { with specimen }\end{array}$ & 5.992 & 0.204 & 8275 \\
\hline Arkansas novaculite; 2.642 & $\begin{array}{l}\text { C; } 2.5 \mathrm{~mm} \text { EL-506D in contact } \\
\text { with specimen }\end{array}$ & $\begin{array}{l}6.112 \\
6.104 \\
6.096 \\
6.091 \\
6.080 \\
6.20\end{array}$ & $\begin{array}{l}0.336 \\
0.306 \\
0.282 \\
0.256 \\
0.234 \\
1.415\end{array}$ & 7695 \\
\hline Sioux quartzite; 2.640 & $\begin{array}{l}\mathrm{C} ; 50.8 \mathrm{~mm} \text { Comp B-3 in con- } \\
\text { tact with specimen }\end{array}$ & $\begin{array}{l}5.626 \dagger \\
\mathbf{5 . 5 6 1} \dagger \\
\mathbf{5 . 5 4 1} \dagger \\
\mathbf{5 . 4 9 9 \dagger} \\
5.477 \dagger \\
4.881 \\
4.829 \\
4.759 \\
4.620 \\
4.546\end{array}$ & $\begin{array}{l}0.249 \dagger \\
0.206 \dagger \\
0.168 \dagger \\
0.106 \dagger \\
0.066 \dagger \\
0.615 \\
0.787 \\
0.703 \\
0.508 \\
0.342\end{array}$ & 7468 \\
\hline Eureka quartzite; 2.640 & $\begin{array}{l}\text { C; } 6.4 \mathrm{~mm} \text { Comp B-3 in contact } \\
\text { with specimen }\end{array}$ & $\begin{array}{r}5.616 \dagger \\
5.648 \dagger \\
\mathbf{5 . 6 7 1} \dagger \\
\mathbf{5 . 6 9 6 \dagger} \\
(\mathbf{4 . 8 5 6 )}\end{array}$ & $\begin{array}{r}0.253 \dagger \\
0.319 \dagger \\
0.222 \dagger \\
0.174 \dagger \\
(0.313)\end{array}$ & 7998 \\
\hline
\end{tabular}

* Experimental arrangements

A, plane-wave inclined mirror

B, plane-wave wedge Representative data cited, listed in order of distance from explosive.

$\mathrm{C}$, two-dimensional wedge

$\dagger$ Intermediate shock state.

( ) Questionable value.

shock. These hypothetical shock and particle velocities are combined for $x, y$, and $z$ cuts and are analytically fitted to straight lines in different stress ranges. The straight line obtained by Wackerle for the second-wave data below 144 $\mathrm{kb}$ has been fitted for the present purpose to a stress-volume curve of the Murnaghan [1951] form

$$
\sigma=\beta\left[\left(V_{0} / V\right)^{\xi}-1\right]
$$

where $\beta=45.07 \mathrm{~kb}$ and $\xi=7.839$. (This procedure, rather than direct conversion to the Murnaghan form, is adopted only for convenience.) Comparison with Bridgman's [1948] isothermal dilatometric measurements is also useful in interpreting shock-wave data. Bridgman's data in the Murnaghan form are $\beta=42.75 \mathrm{~kb}$ and $\xi=8.390$. These are shown in Figure 10 .

Agreement between the reduced Hugoniot data of Wackerle, the static data of Bridgman, 


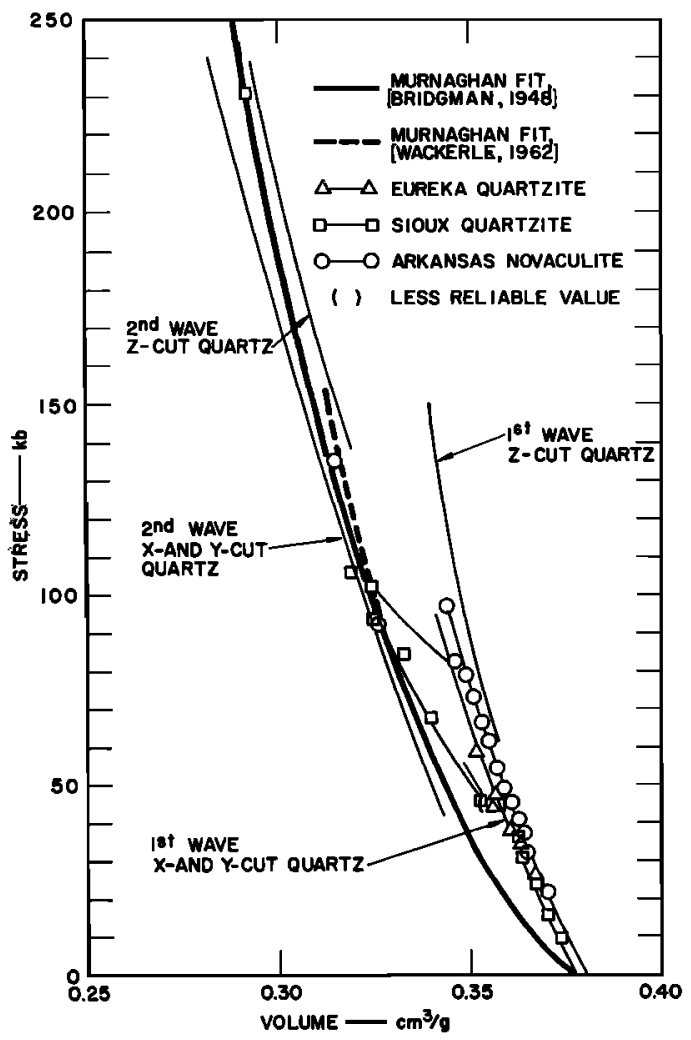

Fig. 10. Hugoniot, quartz and solid quartz rocks.

and states achieved via a second wave in various specimens of polycrystalline quartz is noteworthy. However, several unexplained phenomena remain: (1) The differences in Hugoniots for different crystallographic directions in quartz immediately above the HEL are not adequately described by present models of material behavior under shock compression.

With shock travel, there is an apparent decrease of the HEL stress level when driven by a second shock. This phenomenon, which is also observed in several other materials, is apparently a relaxation of elastic stress. It was inferred to occur in single-crystal quartz by both Wackerle [1962] and Fowles [1961b] and observed directly in Sioux quartzite in the present study (Table 3, shot 7468; see also Duvall and Fowles [1963]). (3) The HEL of polycrystalline quartz rocks is observed to range from approximately $97 \mathrm{~kb}$ for Arkansas novaculite to $59 \mathrm{~kb}$ for Eureka quartzite and to $40 \mathrm{~kb}$ for Sioux quartzite. Although these particular rocks were not chosen for specific variations in rock properties, differences in cementation and mechanical interlocking of grains may be the cause of this large variation of HEL.

Several attempts were made to prepare specularly reflecting surfaces of polycrystalline quartz so that the two-dimensional and planewave wedge method could be applied without the use of metal mirrors. Although such surfaces were attainable, their reflectivity is unfortunately immediately lost above HEL stress levels. Only states substantially below the HEL in quartz rocks are observable by using bare rock as the reflecting surface.

Sandstones. The Hugoniots of Coconino, Massillon, and St. Peter sandstones were obtained up to pressures of 186,25 , and $25 \mathrm{~kb}$, respectively. The first two were essentially identical for shocks below $25 \mathrm{~kb}$ (Figure 11). St. Peter sandstone shows a higher shock impedance, probably due to its lower porosity. Longitudinal elastic-wave velocities determined by conventional ultrasonic travel-time methods at zero pressure are $3.25 \pm 0.18 \mathrm{~mm} / \mu \mathrm{sec}, 3.18$ $\pm 0.22 \mathrm{~mm} / \mu \mathrm{sec}$, and $3.33 \pm 0.10 \mathrm{~mm} / \mu \mathrm{sec}$ for Massillon, St. Peter, and Coconino sandstones, respectively. These correlate to only a fair degree (of the order of $\pm 15 \%$ ) with elastic shock velocities (Table 4).

The two-dimensional wedge method is used to obtain shock states up to only the HEL. In the case of the two-wave shock the inclined mirror and plane-wave wedge techniques are used. For these methods, the HEL is computed from freesurface velocity measurements, and the final state is computed by an impedance-match solution by using the HEL as the initial state. The general indistinctness and unevenness of the streak camera cutoffs (Figure 12) for porous rock are believed to produce some of the scatter in the data, particularly at free-surface velocities of less than $2 \mathrm{~mm} / \mu \mathrm{sec}$. For some of the streak camera records, where resolution of the streak cutoff permitted, a correction for shock attenuation could be applied. The effect on shock planarity of rarefaction waves emanating from the specimen edges limited most of the experiments to specimens between 5 and $13 \mathrm{~mm}$ thick and 20 to $50 \mathrm{~mm}$ in diameter, using a 6or 8-in.-diameter explosive lens. For these dimensions the size of the rock grains, particularly when they are as large as $0.5 \mathrm{~mm}$, undoubtedly 


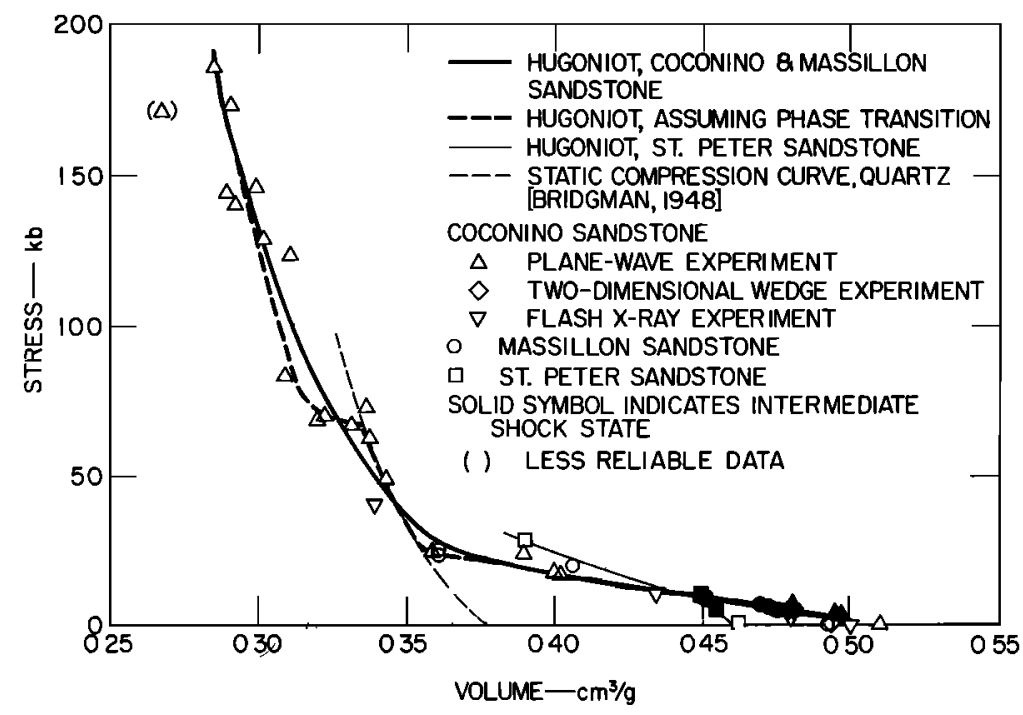

Fig. 11. Hugoniot, sandstone.

affects the reproducibility of free-surface velocity measurements.

The HEL's of the three sandstones studied, taking streak camera record quality into account, characteristically lie between 4.1 and 5.1 kb. The free-surface velocities corresponding to rarefaction from final states above the HEL are shown in Figure 13; these were not used in calculating the shock states. Although the freesurface velocity data in this range are not entirely self-consistent, they and the Hugoniot curve imply that above the elastic limit to approximately $25 \mathrm{~kb}$ successively higher stress states are achieved via what is perhaps an irreversible crushing of the sandstone up to the quartz density. Figure 13 also suggests that the compressed sandstone, in states between $\mathbf{5 0}$ and $130 \mathrm{~kb}$, rarefies along a stress-particle velocity curve close to that which would be expected if the material produced by the shock were solid quartz. Actually, a correct model would be more complicated, since at approximately $37 \mathrm{~kb}$ the Hugoniot points for Coconino sandstone lie consistently at smaller volumes than that of either single or polycrystalline quartz. The implication of this behavior in relation to the temperature achieved during shock compression is considered below.

To obtain an approximate independent confirmation of the Hugoniot data gathered from the above-described optical methods, we per- formed a less refined but perhaps more direct experiment with flash X-ray equipment. The data listed under shot 8269 in Table 4 were obtained from the $\mathrm{X}$-ray shadowgraph shown in Figure 14. As in measurement by the two-dimensional wedge method, the detonation velocity $D$ of a sheet of explosive was obtained by timing the closure of pin switches, while the angle of the shock front $\psi$ was related to $D$ and the shock velocity $U$ by $\sin \psi=U / D$. The particle velocity immediately behind the shock was obtained form the bending angle, $\alpha$, of $0.025-\mathrm{mm}$ silver foils placed between 6-mm-thick slabs of specimen material. At the intersection of a foil with the shock front, the particle velocity $u$ was obtained from $(U-u) / U=\tan (\psi-\alpha) / \tan \psi$. Although under certain conditions a multiwave shock structure has been observed in similar radiographs in different mediums [Rempel, 1963], the shock visible in Figure 14 corresponds to that of the final shock state.

Calculation of shock temperature in sandstone. The temperatures achieved in nonporous rocks and minerals during shock compression are rather moderate. For many nonporous solids the temperature achieved upon shock compression and subsequent adiabatic relaxation is approximately calculable by the method described by Walsh and Christion [1955]. To date, temperatures reached by shock-wave compression of porous rocks have not been specifically discussed. 
TABLE 4. Hugoniot Data, Porous Quartz Rocks

\begin{tabular}{|c|c|c|c|c|}
\hline $\begin{array}{l}\text { Specimen Type; } \\
\text { Initial Density, } \\
\mathrm{g} / \mathrm{cm}^{3}\end{array}$ & $\begin{array}{c}\text { Experimental Arrangement; }{ }^{*} \\
\text { Explosive Driver System; } \\
\text { Driver Free-Surface Velocity, } \\
\mathrm{mm} / \mu \mathrm{sec}\end{array}$ & $\begin{array}{l}\text { Shock } \\
\text { Velocity, } \\
\mathrm{mm} / \mu \mathrm{sec}\end{array}$ & $\begin{array}{l}\text { Particle } \\
\text { Velocity, } \\
\mathrm{mm} / \mu \mathrm{sec}\end{array}$ & $\begin{array}{l}\text { SRI } \\
\text { Shot } \\
\text { No. }\end{array}$ \\
\hline Coconino sandstone; 2.00 & $\mathrm{~A} ; 5 ; 1.178$ & 2.793 & 0.875 & 8151 \\
\hline Coconino sandstone; 1.97 & $\mathrm{~B} ; 5 ;(1.50)$ & 3.11 & 1.09 & 7862 \\
\hline Coconino sandstone; 1.975 & $\mathrm{~A} ; 5 ;(1.54)$ & 3.062 & 1.128 & 7861 \\
\hline Coconino sandstone; 1.96 & $\mathrm{~B} ; 12 ; 2.56$ & 4.26 & 1.75 & 7809 \\
\hline Coconino sandstone; 2.00 & $\mathrm{~B} ; 15 ; 2.93$ & $(4.29)$ & 1.995 & 8164 \\
\hline Coconino sandstone; 2.031 & $\begin{array}{l}\text { C; } 1.5 \mathrm{~mm} \mathrm{EL-506D} \text { in contact } \\
\text { with specimen }\end{array}$ & $\begin{array}{l}3.060 \dagger \\
3.007 \dagger\end{array}$ & $\begin{array}{l}0.085 \dagger \\
0.090 \dagger\end{array}$ & 8269 \\
\hline Coconino sandstone; 2.000 & $\begin{array}{l}\text { D; } 5.1 \mathrm{~mm} \text { EL-506D in contact } \\
\text { with specimen }\end{array}$ & $\begin{array}{l}2.483 \\
2.002 \\
1.601\end{array}$ & $\begin{array}{l}0.796 \\
0.266 \\
0.066\end{array}$ & 8262 \\
\hline \multirow[t]{3}{*}{ Coconino sandstone; 1.961} & $\begin{array}{l}\mathrm{A} ; 12 ; 2.568 \\
\mathrm{~A} ; 13 ; 2.206\end{array}$ & $\begin{array}{l}4.126 \\
4.039\end{array}$ & $\begin{array}{l}1.74 \\
1.53\end{array}$ & 8974 \\
\hline & $\begin{array}{l}A ; 10 ; 1.77 \\
\mathrm{~A} ; 11 ; 1.54\end{array}$ & $\begin{array}{l}3.285 \\
3.141\end{array}$ & $\begin{array}{l}1.26 \\
1.11\end{array}$ & 8975 \\
\hline & $\begin{array}{l}\mathrm{A}, 3 ; 2.46 \\
\mathrm{~A} ; 4 ; 2.25\end{array}$ & $\begin{array}{l}3.321 \\
3.126\end{array}$ & $\begin{array}{l}1.09 \\
1.02\end{array}$ & 8989 \\
\hline Coconino sandstone; 1.961 & $\mathrm{~A} ; \mathbf{1 7} ; 0.836$ & $\begin{array}{l}2.622 \dagger \\
2.305 \\
2.853 \dagger \\
2.385\end{array}$ & $\begin{array}{l}(0.156 \dagger) \\
0.371 \\
0.074 \dagger \\
0.371\end{array}$ & 9107 \\
\hline Massillon sandstone; 2.039 & & $\begin{array}{l}2.861 \dagger \\
2.553\end{array}$ & $\begin{array}{l}\left(\begin{array}{ll}0 & 109\end{array}\right) \\
0.354 \dagger\end{array}$ & 9107 \\
\hline Coconino sandstone; 1.961 & A; 15 & 4.600 & 1.98 & 9106 \\
\hline Coconino sandstone; 1.961 & $A ; 8 ; 1.076$ & $\begin{array}{l}2.705 \dagger \\
2.354 \\
3.027 \dagger \\
2.357\end{array}$ & $\begin{array}{l}(0.151) \dagger \\
0475 \\
0.086 \dagger \\
0500\end{array}$ & 9208 \\
\hline Massillon sandstone; 2.039 & $\mathrm{~A} ; 8 ; 1.076$ & $\begin{array}{l}2.540 \dagger \\
2.111 \\
2.857 \dagger \\
2.503\end{array}$ & $\begin{array}{l}0.080 \dagger \\
0.508 \\
(0.120 \dagger) \\
0.472\end{array}$ & 9215 \\
\hline St. Peter sandstone; 2.141 & $\mathrm{~A} ; 8 ; 1.076$ & $\begin{array}{l}3.579 \dagger \\
3.670 \dagger \\
2.980\end{array}$ & $\begin{array}{l}(0.142 \dagger) \\
(0.058 \dagger) \\
0.42\end{array}$ & 9209 \\
\hline Coconino sandstone; 1.961 & $\mathrm{~A} ; 14 ;(2.872)$ & 4.633 & 2.041 & 9342 \\
\hline
\end{tabular}

* Experimental arrangements

A, plane-wave inclined mirror

$B$, plane-wave wedge

$\mathrm{C}$, two-dimensional wedge Representative states listed in order of distance from explosive.

$D$, two-dimensional $X$ ray

† Hugoniot elastic limit.

( ) Less reliable value. 


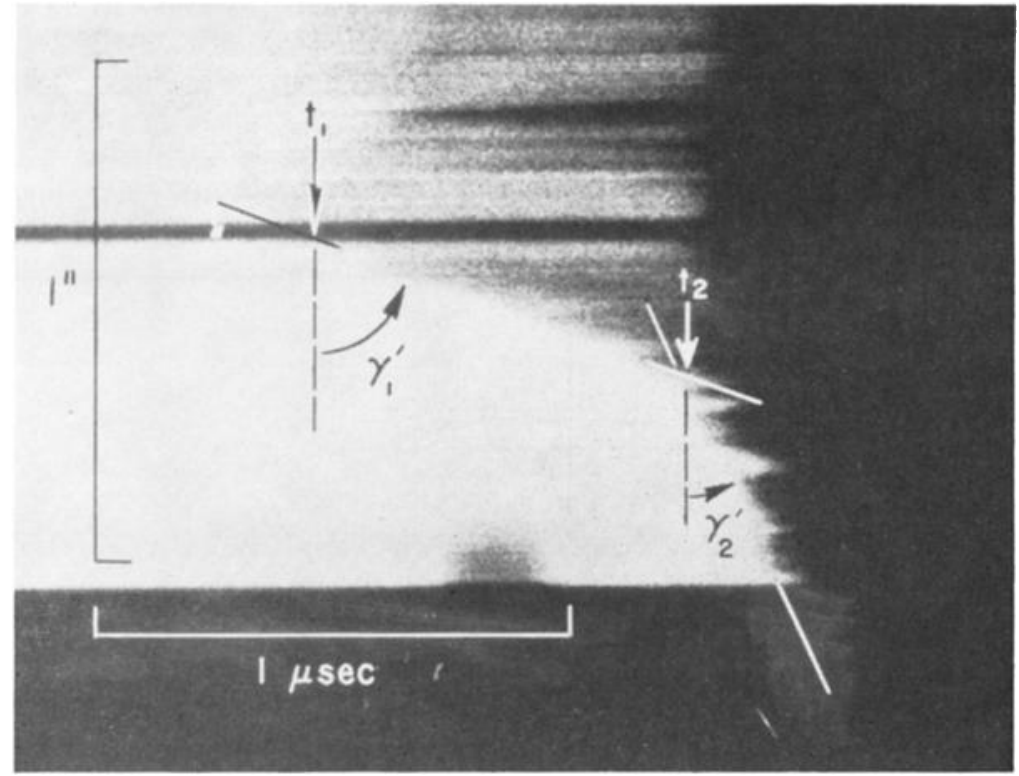

Fig. 12. Streak camera record of inclined mirror cutoff, Coconino sandstone, shot 9107; first wave $(4.1 \mathrm{~kb})$ arrives at $t_{1}$, producing cutoff $\gamma_{1}^{\prime}$; second wave $(18 \mathrm{~kb})$ arrives at $t_{2}$, producing cutoff $\boldsymbol{\gamma}_{2}^{\prime}$.

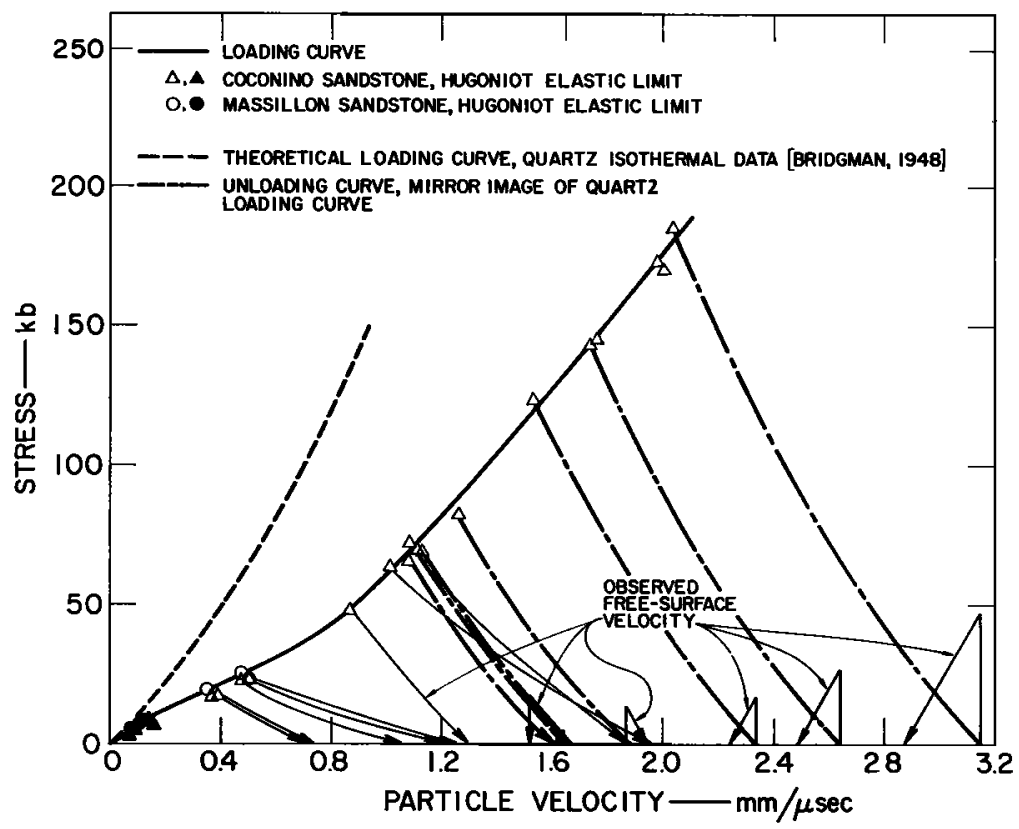

Fig. 13. Stress-particle velocity, Coconino and Massillon sandstones. 


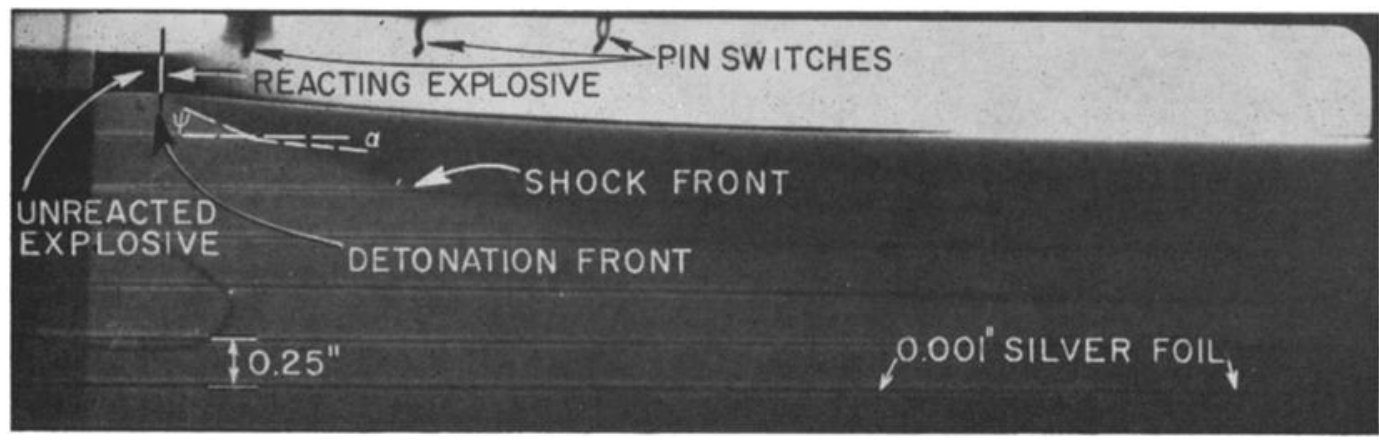

Fig. 14. Flash X-ray shadowgraph, oblique shock in slabs of Coconino sandstone.

Calculations of temperatures in porous metals are discussed by Kormer et al. [1960].

The difference in internal energy per unit mass for shock compression of a porous rock to state $V, \sigma$ (Figure 15) is given by (3). The difficulty in calculating the temperature achieved by a shock transition lies in determining how $E_{1}-E_{0}$ is partitioned into compressional energy, $E_{k}$, and thermal energy, $E_{\imath}$. Thus

$$
E=E_{1}-E_{0}=E_{\imath}+E_{k}
$$

Appropriate latent heats of transformation can be included in $E_{t}$. It is convenient to calculate shock temperatures separately for each of the four regimes of the Hugoniot curve of Figure 15.

The elastic regime, or regime $I$, extends from $V_{0}, \sigma_{0}=0$ to $V_{e}, \sigma_{e}$. For a shock in which the highest stress obtained is below $\sigma_{e}$, the temperature is simply estimated by assuming adiabatic

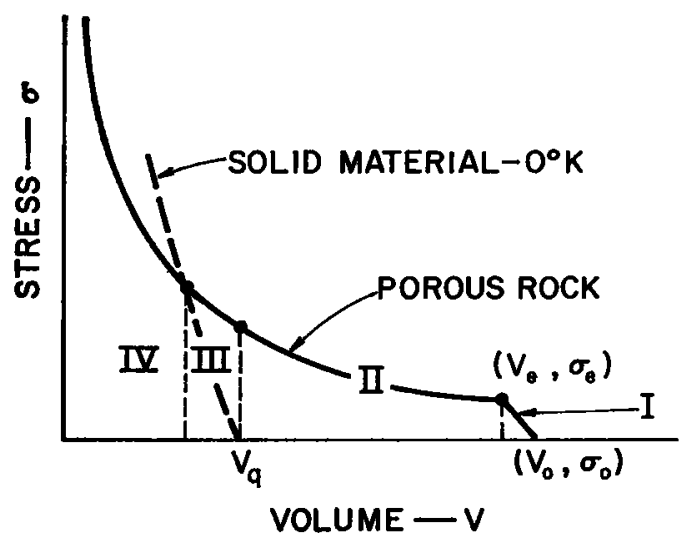

Fig. 15. Hypothetical Hugoniot for porous quartz rock indicating different regimes considered in temperature calculations. compression. This is justified because the elastic shock front in both porous sandstones and limestones travels with a velocity approximately equal to the adiabatic longitudinal-wave velocity. In this regime, therefore, the Hugoniot is assumed to lie close to the adiabat. The adiabatic temperature increase is calculated from

$$
\left.T_{h}\right|_{I}=T_{0} \exp \left[\Gamma_{0}\left(V_{0}-V\right) / V_{0}\right]
$$

For several nonporous solids, $\Gamma / V$ is thought to be nearly constant; therefore, the use of (17) seems justified even for porous mediums because of the small variation in $\sigma$ and $V$ in regime I. For Coconino sandstone, for example, the temperature increase achieved upon shock compression to the HEL from (17) is approximately $15^{\circ} \mathrm{C}$. This temperature increase can be neglected when compared with the much greater temperature changes resulting from stronger shocks.

The second regime may be defined as consisting of compressed states lying between volumes $V_{\theta}$ and $V_{q}$. In this region shock compression is considered as consisting primarily of crushing of porous sandstone to the volume of uncompressed single-crystal quartz. The inherent irreversibility of such a process suggests that much of the shock energy will go to thermal energy-the assumption is made that recoverable mechanical energy and contributions to $E_{t}$ from quartz-grain surface energy are negligible. Some implications of these assumptions are to be discussed. Shock energy is then written as

$$
\left.E\right|_{\mathrm{II}}=E_{\imath}=\sigma\left(V_{0}-V\right) / 2
$$

For regime II, in the case of silicate minerals, the Debye temperature is higher than the shock temperature; therefore, a constant value of specific heat-such as $6 \mathrm{cal} / \mathrm{mole} \mathrm{deg}$, the Du- 
long-Petit value - is inappropriate for calculating $T_{h}$ from $E_{t}$. In quartz, typical of common silicates, $C_{v}$ varies by a factor of 1.6 between room temperature and $800^{\circ} \mathrm{K}$ [Kelley, 1949]. Note that, as in calculation of shock temperature in porous metals, the specific heat of the porous rock or mineral is given in terms of mass and is assumed to be the same as that of the solid material-consistent with the assumptions used in obtaining (18). Pressure affects specific heat (at constant pressure) along an adiabat by an amount which is approximately proportional [Birch, 1952, p. 257] to the square root of the density ratio of uncompressed and compressed solid material. In the following, specific heat is assumed to be independent of stress since the maximum compression of solid quartz in regimes II and III is about $9 \%$, corresponding to only a $3 \%$ decrease in specific heat. Thus in regimes II and III the specific heat is assumed to be only a function of the temperature achieved in shock compression.

Kelley's measurements provide $C_{p}$ as a function of temperature, from which $C_{v}$ is calculable (although the difference for the present purpose is negligible). Often $C_{v}$ or $C_{p}$ is expressed as a function of temperature in the form

$$
C_{v}=a+b T-c / T^{2}
$$

where $a, b$, and $c$ are experimentally determined constants.

Then

$$
\left.E_{t}\right|_{\mathrm{II}}=\int_{r_{\bullet}}^{T_{b}} C_{v} d T
$$

For states in regime II the temperature may implicitly be expressed as

$$
\begin{array}{r}
0=T_{h}^{3}+\frac{2 a}{b}{T_{h}}^{2}-\frac{2}{b}\left[\sigma \frac{\left(V_{0}-V\right)}{2}\right. \\
\left.+a T_{0}+\frac{b T_{0}{ }^{2}}{2}+\frac{c}{T_{0}}\right] T_{h}+\frac{2 c}{b}
\end{array}
$$

where (18) and (19) were substituted into (20). Equation 21, a cubic equation, may be solved for $T_{h}$, the temperature achieved in a shock compression to volumes in the range $V_{q} \leq V \leq V_{e}$ :

In regime III a partition of shock energy is assumed. The total internal energy change due to the shock is

$$
\begin{aligned}
\left.E\right|_{\mathrm{III}}=\left(V_{0}\right. & -V) \sigma / 2 \\
& =\int_{T_{0}}^{T_{h}} C_{v}(T) d T+E_{k}
\end{aligned}
$$

The low value of thermal expansion coefficient for nonmetallic materials such as silicates and, in particular, quartz suggests that the $0^{\circ} \mathrm{K}$ isotherm can be approximated by an isothermal compression curve like the one determined statically at room temperature by Bridgman. Thus the $0^{\circ} \mathrm{K}$ isotherm is approximately given by the Murnaghan equation 15, where again $\beta=42.75$ $\mathrm{kb}, \xi=8.390$, and $V_{\mathrm{v}}$ is associated with $V_{q}$. The compressional shock energy is given by

$$
E_{k} \approx \int_{\mathrm{V}_{\mathrm{q}}}^{\mathrm{v}}-\left[\begin{array}{ll}
\sigma & d V
\end{array}\right] 0^{\circ} \mathrm{K}
$$

which upon substitution of (15) and integration becomes

$$
\begin{aligned}
E_{k} & =V_{a} \beta \\
& \cdot\left[\frac{\left(V_{q} / V\right)^{\xi-1}-1}{\xi-1}+V / V_{q}-1\right]
\end{aligned}
$$

Therefore, the temperature of porous sandstone at final states of compression in regime III may be implicitly written as

$$
\begin{aligned}
0 & =T_{h}{ }^{3}+\frac{2 a}{b} T_{h}{ }^{2}-\frac{2}{b}\left\{\sigma \frac{\left(V_{0}-V\right)}{2}\right. \\
& -V_{a} \beta\left[\frac{\left(V_{a} / V\right)^{\xi-1}-1}{\xi-1}+V / V_{a}-1\right] \\
& \left.+a T_{0}+\frac{b T_{0}{ }^{2}}{2}+\frac{c}{T_{0}}\right\} T_{h}+2 c / b
\end{aligned}
$$

where (24) and (19) are substituted into (22). The fact that the volumes achieved by shocked sandstone are less than those achieved by quartz upon isothermal compression must be considered in calculating the temperature for regime IV. At a given state in regime IV it is assumed (see Discussion, below) that the shocked material contains a mixture of quartz and stishovite which has a specific volume given by $V=q V_{Q}$ $+(1-q) V_{s}$.

In terms of volume, $q$ is written as

$$
q=\left(V-V_{s}\right) /\left(V_{Q}-V_{s}\right)
$$

For purposes of computation, $V_{s}$ and $V_{Q}$ are taken to be specific volumes along an assumed 
$0^{\circ} \mathrm{K}$ isotherm. Since $V$ is actually the volume along the Hugoniot, the $q$ obtained from (26) is slightly in error. The compressional shock energy, now a function of the specific volumes of both $\mathrm{SiO}_{2}$ phases, is

$$
E_{k}=q E_{k}^{a}+(1-q) E_{k}{ }^{*}
$$

For quartz, $E_{k}{ }^{q}$ is obtained from (24).

Using Wackerle's [1962] quartz and fused data, McQueen et al. [1963] calculated a hypothetical stishovite Hugoniot appropriate for achievement of shock states from zero-pressure material. Although further refinement is possible, for the present purposes this Hugoniot is assumed to approximate the stishovite $0^{\circ} \mathrm{K}$ isotherm and is analytically expressed in terms of shock and particle velocity as

$$
U_{1}=C_{0}+S u_{1}
$$

where $C_{0}$ is $1.0 \times 10^{\circ} \mathrm{cm} / \mathrm{sec}$ and $S$ is 1.0 . Combining (27) with (1) and (2) yields

$$
\begin{aligned}
\sigma_{1}=\sigma_{0}+C_{0}{ }^{2}\left(V_{0 S}-V_{S}\right) /\left[V_{0 S}\right. \\
\left.-S\left(V_{0 S}-V_{S}\right)\right]^{2}
\end{aligned}
$$

Upon substitution and integration, (23) yields

$$
\begin{aligned}
& E_{k}{ }^{3}=C_{0}^{2}\left\{\ln \left[1-S\left(1-V_{s} / V_{0 s}\right)\right]\right. \\
& \left.+\left[1-S\left(1-V_{S} / V_{0 S}\right)\right]^{-1}-1\right\} / S^{2}
\end{aligned}
$$

where $\sigma_{0}=0$.

The choice of specific heat value for the regime IV temperature calculations is unfortunately somewhat arbitrary. From consideration of the quartz specific heat, which is at almost the Dulong-Petit value of $12.3 \times 10^{\circ} \mathrm{ergs} / \mathrm{gdeg}$ in the vicinity of $800^{\circ} \mathrm{K}$, this value is adopted as a constant value for the quartz-stishovite mixture. The shock temperature, $T_{\mathrm{h}}{ }^{\prime}$ in regime IV, if the latent heat of phase transformation is neglected, is

$$
\begin{aligned}
& \left.\left(T_{h}{ }^{\prime}-T_{0}\right) C_{v}\right|_{\mathrm{IV}} \\
& \quad \approx E-q E_{k}{ }^{a}-(1-q){E_{k}}^{s}
\end{aligned}
$$

where the three terms on the right are obtained by using (3), (24), and (29), respectively. The small additional temperature increase resulting from the heat of the hypothetical (exothermic) quartz-stishovite transition, derived from the Clapeyron equation, is approximately

$$
\begin{aligned}
& T_{h}-T_{h}^{\prime} \\
& \approx \frac{(1-q)\left(V_{Q}-V_{S}\right) T_{h}{ }^{\prime}}{\left.C_{v}\right|_{I V}}\left(\frac{d P}{d T}\right)_{a-s}
\end{aligned}
$$

where $(d P / d T)_{q:}=17.7 \times 10^{6}$ dynes $/ \mathrm{cm}^{2} \mathrm{deg}$ is the slope (assumed constant) of the quartzstishovite phase line; this value is estimated from thermodynamic data in the next section.

The shock temperatures in Coconino sandstone (Table 5, Figure 16) are calculated using (21) for both regimes I and II, (25) for regime III, and (30) and (31) for regime IV. The sudden decrease in temperature between regimes III and IV is artificially introduced by the assumption of the Dulong-Petit specific heat value in the latter regime. Some of the errors which arise in the above temperature estimate are now considered.

Table 5 temperatures can be considered minimal for the following reasons: (1) It is implicitly assumed in all regimes that thermal equilibrium behind the shock is achieved; i.e., shock-energy density is evenly distributed within the shocked material. It is conceivable that, in an aggregate of shocked quartz grains, more thermal energy should be concentrated at grain boundaries than within grains, thereby producing high local temperatures. The relaxation time required for thermal equilibrium should depend on grain size and thermal properties of the shocked material. (2) The specific heat assumed in regime IV for the quartz-stishovite mixture, $12.3 \times 10^{\circ}$ ergs/g deg being a maximum, and excluding possible electronic or anharmonic contributions, may be slightly too high, resulting in temperatures which are too low. (3) At present it is not clear whether the surface energy of a porous rock will increase or decrease during shock compression. However, the large volume decrease during shocking suggests that the initial surface energy is released. For spherical particles, $\Omega=$ $3 \tau / r_{\beta_{0}}$. For quartz, $\tau$ is of the order of $10^{3} \mathrm{ergs} /$ $\mathrm{cm}^{2}$ [Brace and Walsh, 1962]. Hence particles of the order of $10^{-6} \mathrm{~cm}$ in radius are required if the surface energies are to be comparable with the shock energies of Table 5. (4) The pressure effect on the specific heat of quartz, as mentioned above, results in a slight underestimate in regimes II and III. The zero-pressure value used 
may be $3 \%$ too high at the highest shock stress.

The following overestimates of the shock temperature are recognized.

1. What appears to be the irreversible nature of shock compression to states in regime II suggests that most of the shock energy should go into heat. However, from the Mie-Grüneisen equation (see e.g. Rice et al. [1958]) it is possible to predict the thermal pressure achieved by quartz remaining at its normal uncompressed volume upon addition of an amount of internal energy which corresponds to the maximum shock energy in regime II. From Table 5 the thermal energy for quartz at this point is $E_{1}=1.458 \times 10^{\circ} \mathrm{ergs} / \mathrm{g}$; while in terms of the Mie-Grüneisen equation the initial energy and pressure are zero. The thermal pressure is $P_{t}=\Gamma E_{t} / V_{0}$. For $\Gamma=0.653, P_{t}=2.53 \mathrm{~kb}$ (far less than the $22.0 \mathrm{~kb}$, or even the HEL stress subtracted from this value), which is observed for sandstone at the volume of uncompressed quartz. It may be concluded that either

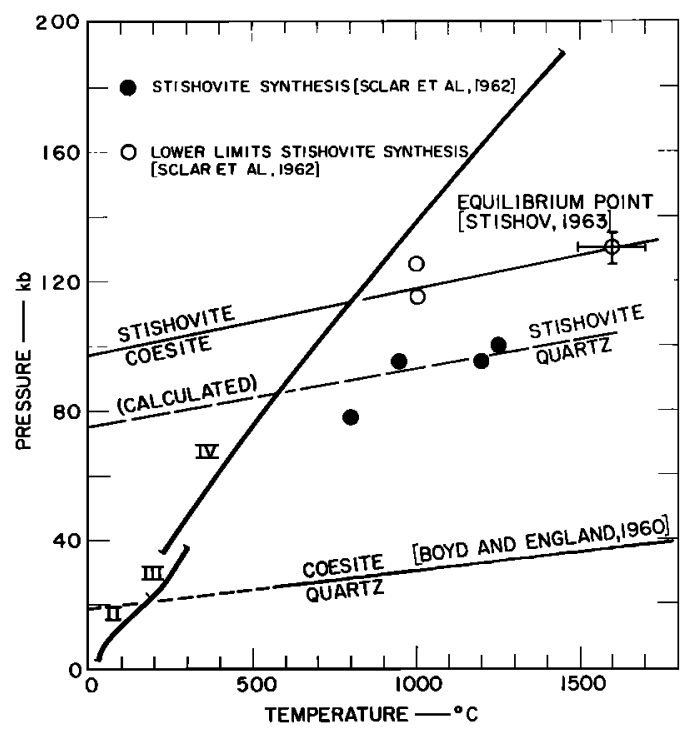

Fig. 16. Calculated temperature achieved along Hugoniot, Coconino sandstone, relation to $\mathrm{SiO}_{2}$ phase diagram.

TABLE 5. Shock Temperatures, Coconino Sandstone

\begin{tabular}{|c|c|c|c|c|}
\hline Regime & $\begin{array}{l}\text { Stress, } \\
\text { kb }\end{array}$ & $\begin{array}{c}\text { Shock Energy } \\
E, \text { ergs } / \mathrm{g} \times 10^{-9}\end{array}$ & $\begin{array}{c}\text { Thermal Energy } \\
E_{T}, \text { ergs } / \mathrm{g} \times 10^{-9}\end{array}$ & $\begin{array}{c}\text { Shock } \\
\text { Temperature } \\
T_{h},{ }^{\circ} \mathrm{C}\end{array}$ \\
\hline II & $\begin{array}{r}2.5 \\
6.5 \\
7.0 \\
9.0 \\
12.0 \\
15.5 \\
19.5 \\
22.0\end{array}$ & $\begin{array}{l}0.0244 \\
0.0959 \\
0.138 \\
0.268 \\
0.477 \\
0.721 \\
1.046 \\
1.458\end{array}$ & $\begin{array}{l}0.0244 \\
0.0959 \\
0.138 \\
0.268 \\
0.477 \\
0.721 \\
1.046 \\
1.458\end{array}$ & $\begin{array}{r}30 \\
40 \\
46 \\
64 \\
90 \\
117 \\
153 \\
195\end{array}$ \\
\hline III & $\begin{array}{l}22.0 \\
23.5 \\
25.4 \\
28.0 \\
30.0 \\
32.0 \\
34.3 \\
36.8\end{array}$ & $\begin{array}{l}1.458 \\
1.639 \\
1.835 \\
2.093 \\
2.287 \\
2.472 \\
2.701 \\
2.935\end{array}$ & $\begin{array}{l}1.458 \\
1.629 \\
1.775 \\
1.953 \\
2.077 \\
2.202 \\
2.041 \\
2.515\end{array}$ & $\begin{array}{l}195 \\
212 \\
229 \\
245 \\
259 \\
271 \\
292 \\
302\end{array}$ \\
\hline IV & $\begin{array}{r}36.8 \\
42.0 \\
52.8 \\
64.0 \\
73.0 \\
89.0 \\
104.5 \\
113.5 \\
149.5 \\
190.0\end{array}$ & $\begin{array}{r}2.935 \\
3.465 \\
4.567 \\
5.744 \\
6.748 \\
8.589 \\
10.424 \\
11.747 \\
16.071 \\
21.328\end{array}$ & $\begin{array}{r}2.515 \\
2.948 \\
3.828 \\
4.747 \\
\mathbf{5 . 5 1 7} \\
7.002 \\
\mathbf{8 . 4 7 2} \\
9.585 \\
12.987 \\
17.264\end{array}$ & $\begin{array}{r}229 \\
265 \\
337 \\
411 \\
476 \\
598 \\
720 \\
815 \\
1096 \\
1452\end{array}$ \\
\hline
\end{tabular}


the thermal pressure is as low as indicated by the Mie-Grïneisen equation for quartz and the higher observed shock pressure is produced by rigidity of sandstone above the HEL, producing a temperature overestimate in regime II, or the shocked material has thermodynamic properties corresponding to a larger effective value of $(d P / d T)$, than single-crystal quartz. In these calculations the latter has been implicitly assumed.

2. The specific volumes achieved in regime IV are observed to be consistently less than those of quartz and are assumed to result from coexistence of stishovite and quartz. This supposition is considered in the next section. If, as suggested by the phase diagram, some or even all of the high-pressure phase consists of lowerdensity coesite below $85 \mathrm{~kb}$, the compressional energy could be underestimated, resulting in temperature overestimates.

3 . The possible presence of significant shearstress energy in the shocked material is generally not taken into account in the consideration of shock energy partition for shock temperature calculations. The assumption of essentially fluid behavior for shocks above the HEL in materials containing quartz may not be completely valid in view of the significant anisotropy observed for Hugoniot states achieved by high-intensity shocks.

Discussion, Shock-wave compression of sandstone. The smooth curve representation of the Coconino sandstone Hugoniot in Figure 11 (solid line) is particularly interesting for stresses above $37 \mathrm{~kb}$. Normally the Hugoniot of a porous material would be expected to lie toward greater volume states than that of either the isotherm or Hugoniot of the solid material; this is so because of the entropy gained in the shock transition. In contrast, the volumes in the shock state achieved by Coconino sandstone are significantly less than those achieved at the same stress in static isothermal compression or by shocking initially solid quartz. Furthermore, the deviation of the sandstone Hugoniot from the static quartz compression curve above $37 \mathrm{~kb}$ is in the sense opposite to that produced by nonzero rigidity in the shocked material.

The loci of temperature-pressure states which are estimated in the preceding section for regimes II and II suggest that, for at least the solid-line Hugoniot of Figure 11, the shocked material may be within the stability range of coesite, near $37 \mathrm{~kb}$ (Figure 16). The high-pressure states attained in regime IV suggest eventual entrance into the pressure-temperature range for stishovite stability. Thus an alternative interpretation of the data points is the revised Hugoniot indicated by the dashed curve of Figure 11. This hypothetical configuration implies compression of sandstone to essentially quartz equilibrium states up to $67 \mathrm{~kb}$, at which stress a transition to coesite or possibly stishovite is indicated. The estimated shock temperatures are insensitive to minor deviations of the Hugoniot.

Continuing with the original (solid) Hugoniot curve, an incremental temperature increase due to latent heat of transformation was taken into account in the preceding section by assuming partial conversion to stishovite above $37 \mathrm{~kb}$. The latent heat is estimated from the slope of a hypothetical quartz-stishovite phase equilibrium line, this being approximately calculable from standard entropies and volumes of quartz, coesite, and stishovite. Stishov [1963] estimated the standard entropy of stishovite as $6.28 \mathrm{cal} / \mathrm{deg}$ mole on the basis of the entropydensity correlation of the isostructural series $\mathrm{GeO}_{2}-\mathrm{SnO}_{2}-\mathrm{PbO}_{2}$. A phase-line slope for quartzstishovite of $17.7 \times 10^{\circ}$ dynes $/ \mathrm{cm}^{2} \mathrm{deg}$ is obtained by using $10.00 \mathrm{cal} / \mathrm{deg} \mathrm{mole}$ for the standard quartz entropy and a molar volume of $13.81 \mathrm{~cm}^{3}$ for stishovite and by assuming that $\Delta V / \Delta S$ is constant along the phase line and independent of pressure at $298^{\circ} \mathrm{K}$. The free-energy change at $25^{\circ} \mathrm{C}$ and zero pressure for the quartz-stishovite reaction is obtained from

$$
\begin{aligned}
\Delta{F^{0}}^{0}{ }_{298}=\Delta H^{0}{ }_{298}-T & \Delta{S^{0}}^{0} \\
& =11.0 \times 10^{\circ} \mathrm{ergs} / \mathrm{g}
\end{aligned}
$$

where $\Delta H^{0}{ }_{298}$ and $\Delta S^{0}$ 29a are computed, respectively, from the standard enthalpies and entropies tabulated by Stishov [1963]. The pressure $P$, at the standard temperature $\left(298^{\circ} \mathrm{K}\right)$, required for the change of free energy to be zero for the reaction quartz-stishovite, is implicitly given by

$$
\Delta{F^{0}}_{298}=-\int_{0}^{P}\left(V_{S}-V_{0}\right) d P
$$

where $V_{B}$ and $V_{Q}$, as in the previous section, depend on pressure. Since the standard enthalpy 
TABLE 6. Hugoniot Data, Calcite

\begin{tabular}{|c|c|c|c|c|c|c|c|c|c|c|c|}
\hline \multicolumn{2}{|c|}{ Orientation } & \multirow{2}{*}{$\begin{array}{c}\text { Exploaive } \\
\text { Driver } \\
\text { Assembly;* } \\
\text { Free- } \\
\text { Surface } \\
\text { Velocity, } \\
\mathrm{mm} / \mu \mathrm{sec}\end{array}$} & \multicolumn{2}{|c|}{ First Shock State } & \multicolumn{2}{|c|}{ Second Shock State } & \multicolumn{2}{|c|}{ Third Shock State } & \multicolumn{2}{|c|}{ Final Shock State } & \multirow[b]{2}{*}{$\begin{array}{l}\text { SRI } \\
\text { Shot } \\
\text { No. }\end{array}$} \\
\hline Axis & $\begin{array}{l}\text { Miller } \\
\text { Index }\end{array}$ & & $\begin{array}{l}\text { Particle } \\
\text { Velocity, } \\
\mathrm{mm} / \mu \mathrm{sec}\end{array}$ & $\begin{array}{c}\text { Shock } \\
\text { Velocity, } \\
\mathrm{mm} / \mu 8 \mathrm{e}\end{array}$ & $\begin{array}{l}\text { Particle } \\
\text { Velocity, } \\
\mathrm{mm} / \text { msec }\end{array}$ & $\begin{array}{c}\text { Shock } \\
\text { Velocity, } \\
\mathrm{mm} / \mu \mathrm{sec}\end{array}$ & $\begin{array}{l}\text { Particle } \\
\text { Velocity, } \\
\mathrm{mm} / \text { asec }\end{array}$ & $\begin{array}{c}\text { Shock } \\
\text { Velocity, } \\
\text { mm/usec }\end{array}$ & $\begin{array}{l}\text { Particle } \\
\text { Velocity, } \\
\mathrm{mm} / \mu \mathrm{sec}\end{array}$ & $\begin{array}{c}\text { Shook } \\
\text { Velocity, } \\
\mathrm{mm} / \mu \mathrm{sec}\end{array}$ & \\
\hline Cleav. & [10̄̄1] & $\begin{array}{rr}1 ; 2.175 \\
6 ; 1.174 \\
1.152 \\
2 & \end{array}$ & $\begin{array}{c}0.097 \\
(0.081) \\
0.114\end{array}$ & $\begin{array}{c}7.068 \\
(7.134) \\
7.134 \\
6.955\end{array}$ & $\begin{array}{c}0.333 \\
(0.134)\end{array}$ & $\begin{array}{l}(5.016) \\
(5.040)\end{array}$ & & & $\begin{array}{c}0.625 \\
(0.195) \\
0.269\end{array}$ & $\begin{array}{c}4.639 \\
(3.864) \\
3952\end{array}$ & $\begin{array}{l}8461 \\
8505 \\
8460\end{array}$ \\
\hline \multirow[t]{6}{*}{$z$} & [0001] & $\begin{array}{r}2 ; 1.482 \\
1.400\end{array}$ & $(0.206)$ & 5.385 & $(0.853)$ & $(4.965)$ & & & $\begin{array}{c}0.7312 \\
(1.044)\end{array}$ & $\begin{array}{c}4.652 \\
(4.724)\end{array}$ & 8506 \\
\hline & & $2 ; 1.409$ & 0.139 & 5563 & 0.789 & 4822 & & & 0.865 & 4.051 & 8740 \\
\hline & & $\begin{array}{r}1 ; 2.392 \\
2.399\end{array}$ & 0.119 & 5.752 & & & & & $\begin{array}{l}0.586 \\
0.900\end{array}$ & $\begin{array}{l}(5.128) \\
(5 \quad 128)\end{array}$ & 8852 \\
\hline & & $6 ; 1.408$ & 0.129 & 5.451 & 0.236 & 4.146 & 0.348 & 3.662 & 0.405 & 3.184 & 8853 \\
\hline & & $15^{1.442}$ & 0.123 & 5.407 & 0.221 & 4.222 & 0.350 & 3.591 & 1.514 & 5.981 & 8866 \\
\hline & & $5 ; 1.495$ & 0.103 & 5.758 & & & & & 0.837 & 4.807 & 8943 \\
\hline \multirow[t]{6}{*}{$x$} & {$[\overline{1} 2 \overline{1} 0]$} & 2 & $(0.132)$ & $(7.398)$ & $(0.346)$ & $(5.240)$ & & & $(0.665)$ & $(4.422)$ & 8588 \\
\hline & & $2 ; 1.478$ & 0.120 & 6.955 & 0.681 & 4.740 & & & 0.770 & 4.001 & 8715 \\
\hline & & $1 ; 2.499$ & 0.125 & 6.788 & & & & & 0.682 & 4.699 & 8741 \\
\hline & & $6 ; 1.377$ & 0.109 & 6.886 & 0.228 & 4.441 & & & 0.343 & 3.573 & 8838 \\
\hline & & 15; 3.319 & & & & & & & 1.395 & 6.493 & 8867 \\
\hline & & $6 ; 1.282$ & 0.105 & 6.852 & 0217 & 4227 & & & 0.307 & 3.605 & 8945 \\
\hline \multirow[t]{6}{*}{$y$} & {$[10 \overline{1} 0]$} & $2 ; 1.462$ & 0.145 & 7.122 & 0.554 & 4.765 & & & 0.748 & 4.390 & 8737 \\
\hline & & $1 ; 2.555$ & 0.141 & 7.082 & & & & & 0.687 & 4.582 & 8749 \\
\hline & & $6 ; 1.241$ & 0.135 & 6.955 & 0.222 & 4.290 & & & 0.318 & 3.685 & 8839 \\
\hline & & $15 ; 3.261$ & & & & & & & 1.473 & 6.206 & 8868 \\
\hline & & $7 ; 1.438$ & 0.118 & 6.637 & (0.185) & $(4.327)$ & $(0.285)$ & (3.331) & $(0.331)$ & $(2.860)$ & 8933 \\
\hline & & $2 ; 1.538$ & 0.110 & 7.044 & 0.614 & 4.788 & & & 0.749 & 4.336 & 8944 \\
\hline
\end{tabular}

( ) Date are lesa reliable.

* Plane-wave inclined-mirror techniques.

of stishovite is calculated using only zero-pressure volumes, the change of free energy in (32), to the same degree of approximation, is rewritten as $\Delta F^{\circ}{ }_{208}=\left(V_{q}-V_{\text {os }}\right) P$, yielding $74.9 \mathrm{~kb}$ for $P$. The approximate phase line, for this pressure value and the calculated slope, is shown in Figure 16.

The difference in internal energy between quartz and stishovite under standard conditions is

$$
\begin{aligned}
\Delta{E^{0}}^{0}{ }_{298}=T \Delta S^{0}{ }_{298}+\Delta F^{0}{ }_{298} & \\
& =10.2 \times 10^{9} \mathrm{ergs} / \mathrm{g}
\end{aligned}
$$

which, although comparable in magnitude, differs significantly from the McQueen et al. [1963] value of $15.0 \times 10^{\circ} \mathrm{ergs} / \mathrm{g}$. The disagreement arises principally because of the $144-\mathrm{kb}$ value assumed by McQueen et al. (using Wackerle's [1962] data) for the quartz-stishovite transition.

Calcium carbonate rocks, calcite. A series of plane-wave inclined-mirror experiments were performed on single-crystal calcite specimens oriented so that the plane of the shock was perpendicular to the Miller index direction [ $\overline{1} 2 \overline{1} 0]$ (the $x$ axis), to [1010] (the $y$ axis), to [0001] (the $z$ axis), and to [1011] (the direction of the rhombohedral cleavage) (Table 6). Hugoniots for these orientations demonstrate the existence of what appears to be a complex series of transitions resulting in multiwave shock fronts in various stress ranges. The apparent transitions are indicated by cusps on the Hugoniot curve (Figure 17). These cusps, although not observed in detail in a series of experiments, are inferred from the instability equation (6).

The existence of more than one wave in the shock front (as described by (6)) is demonstrated for $z$-cut calcite by the inset in Figure 17 and Table 7. This is shown as follows: for shocks between 0 and $18.5 \mathrm{~kb}$ (the value of the first instability), a single shock front exists; for 


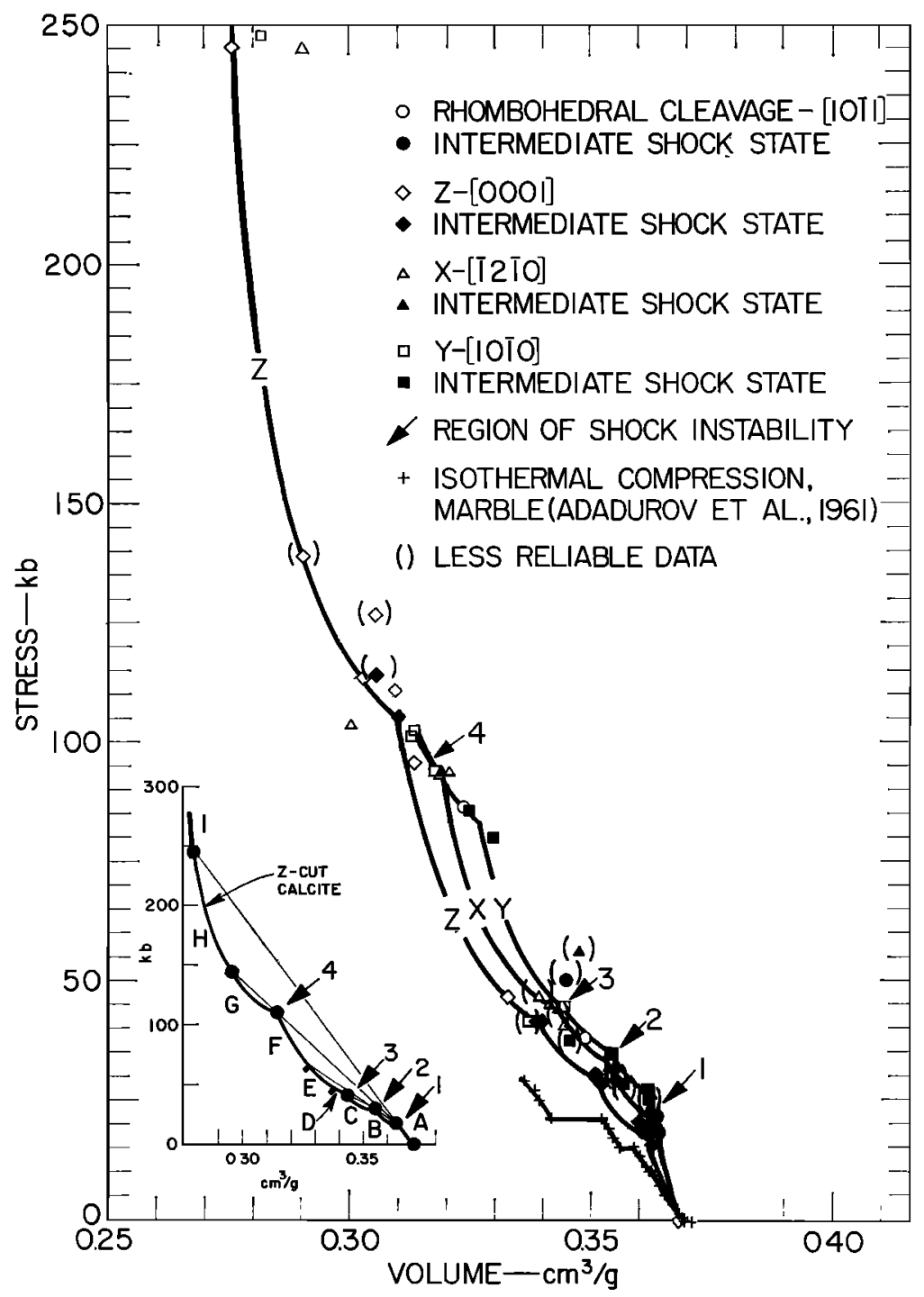

Fig. 17. Hugoniot, calcite.

shocks for which the final state is between 18.5 and $30 \mathrm{~kb}$ (the value of the second instability), two shocks are present; for a final shock state that is between $30 \mathrm{~kb}$ and $42 \mathrm{~kb}$ (the third instability), three shock fronts are present; and in the stress range of 42 to $50.5 \mathrm{~kb}$, four shock fronts are observed. (The streak record of Figure 4 , in which the final state was $46 \mathrm{~kb}$, shows four discrete shock fronts in only one (mirror B) of the inclined-mirror traces; this mirror has the greater inclination (about $2^{\circ}$ ) to the free surface of the specimen, resulting in a longer recording time). As the final state exceeds 50.5 kb by an increasingly greater amount there occurs a triple shock, a double shock, and finally a single shock, the latter being stable above approximately $248 \mathrm{~kb}$.

The shock front from the first instability (Figure 17) is interpreted as arising from the HEL with amplitude varying from 18.5 to 23.7 $\mathrm{kb}$ in different orientations (Table 8). Firstwave shock velocities are in disagreement with longitudinal elastic-wave velocities by up to $5.5 \%$ (in the $y$ direction, (Table 8); the latter have been accurately determined by Peselnick and Robie [1963]. This disagreement is disturb- 
TABLE 7. Shock Stability Regions in $z$-Cut Calcite

\begin{tabular}{cccl}
\hline $\begin{array}{c}\text { Final Shock } \\
\text { State } \\
\text { Region* }\end{array}$ & $\begin{array}{c}\text { Range, } \\
\text { kb }\end{array}$ & $\begin{array}{c}\text { No. of } \\
\text { Fronts }\end{array}$ & $\begin{array}{c}\text { Intermediate } \\
\text { Shok States, } \\
\text { kb }\end{array}$ \\
\hline & $0-18.5$ & 1 & \\
$A$ & $0-5-30.0$ & 2 & 18.5 \\
$B$ & $18.5-30$ \\
$C$ & $30.0-42.0$ & 3 & $18.5,30.0$ \\
$D$ & $42.0-50.5$ & 4 & $18.5,30.0,42.0$ \\
$E$ & $50.5-70.5$ & 3 & $18.5,30.0$ \\
$F$ & $70.5-105.5$ & 2 & 18.5 \\
$G$ & $105.5-140$ & 3 & $18.5,105.5$ \\
$H$ & $140-248$ & 2 & 18.5 \\
$I$ & $>248$ & 1 & \\
\hline
\end{tabular}

* See inset, Figure 17.

ing because it is not easily attributed to scatter in the shock data (Table 6), and, in addition, effective moduli for longitudinal-wave propagation should, for the normal, concave upward Hugoniot, increase with stress amplitude, which is contrary to the observed deviation. It is possible that for the propagation in the $x$ and $y$ directions the elastic waves with velocities equal to that of the ultrasonic measurement had such small amplitudes that they were not recorded. The existence of an elastic-shock velocity lower than the infinitesimal velocity may also occur if the Hugoniot in the region of the HEL is convex upward. The effect on shock propagation by such a region of anomalous compressibility is discussed by Duvall [1961].

Shock states for calcite lying above the ap- parent HEL and also those achieved via one or more additional shock transitions are calculated as outlined by (8). No interaction is assumed between waves reflected at the free surface of the specimen and those following within the specimen. States which presumably correspond to the onset of a polymorphic transition are reproduced in different experiments; these include ones in which both final shock state and number of fronts present are varied. This behavior suggests that points of instability do indeed represent the onset of compression-induced polymorphic phase transitions. Another test of the data is to compare final shock states obtained by successive calculation, using (8) and the observed free-surface velocity profile, with the final states obtained in the shock-stress particle-velocity plane from the impedance-match solution. An example of such a comparison is indicated in Figure 18 for the complex record of shot 8853 ; the close agreement of the two values for the final state suggests the validity of the calculation based on the assumption of no wave interaction. It should be emphasized in the case of phase transitions that use of the free-surface velocity approximation implies that the high-pressure phases transform reversibly along an unloading path which is close to the mirror image of the compression curve, as indicated by $B A^{\prime} O^{\prime \prime \prime}$ in Figure 3.

As an alternative to assuming the approximate validity of (8), a free-surface velocity profile of almost arbitrary complexity may be obtained by assuming interactions of the first

TABLE 8. Stresses and Shock Velocity Associated with Calcite Elastic Limit

\begin{tabular}{|c|c|c|c|c|c|c|c|c|c|c|c|}
\hline \multicolumn{2}{|c|}{$\begin{array}{l}\text { Direction } \\
\text { Shock } \\
\text { Propagation }\end{array}$} & \multirow{2}{*}{$\begin{array}{c}\text { Hugoniot } \\
\text { Elastic } \\
\text { Limit, } \\
\text { kb }\end{array}$} & \multicolumn{3}{|c|}{$\begin{array}{c}\text { Stress Perpen- } \\
\text { dicular to } \\
\text { Shock Travel } \\
\text { Direction } \\
\text { at HEL, }{ }^{*} \\
\text { kb }\end{array}$} & \multicolumn{3}{|c|}{$\begin{array}{c}\text { Principal } \\
\text { Stresses } \\
\text { at HEL, }{ }^{*} \dagger \\
\text { kb }\end{array}$} & \multirow{2}{*}{$\begin{array}{c}\text { Mean } \\
\text { Stress } \\
\text { (Hydro- } \\
\text { static) } \\
\text { at HEL, } \\
\text { kb }\end{array}$} & \multirow{2}{*}{$\begin{array}{c}\text { First Wave } \\
\text { (HEL) } \\
\text { Shock } \\
\text { Velocity, } \\
\mathrm{mm} / \mu \mathrm{sec}\end{array}$} & \multirow{2}{*}{$\begin{array}{l}\text { Average } \\
\text { Value } \\
\text { Ultrasonic } \\
\text { Velocity,* } \\
\mathrm{mm} / \mu \mathrm{sec}\end{array}$} \\
\hline Axis & $\begin{array}{l}\text { Miller } \\
\text { Index }\end{array}$ & & & $y$ & $z$ & $x^{\prime}$ & $y^{\prime}$ & $z^{\prime}$ & & & \\
\hline $\begin{array}{l}x \\
y \\
z \\
\text { leav. }\end{array}$ & $\begin{array}{l}{[\overline{1} 2 \overline{1} 0]} \\
{[10 \overline{1} 0]} \\
{[0001]} \\
{[10 \overline{1} 1]}\end{array}$ & $\begin{array}{l}21.5 \pm 1.6 \\
23.7 \pm 3.4 \\
18.5 \pm 1.8 \\
18.8 \pm 3.3\end{array}$ & $\begin{array}{r}\overline{9.4} \\
12.0\end{array}$ & $\frac{8.4}{12.0}$ & $\begin{array}{l}78 \\
8.8 \\
-\end{array}$ & $\begin{array}{r}21.2 \\
2.6 \\
120\end{array}$ & $\begin{array}{r}5.2 \\
25.5 \\
12.0\end{array}$ & $\begin{array}{r}11.1 \\
6.5 \\
18.5\end{array}$ & $\begin{array}{l}12.5 \\
11.5 \\
14.2\end{array}$ & $\begin{array}{l}6.904 \pm 0.098 \\
6.968 \pm 0.190 \\
5.553 \pm 0.168 \\
7.052 \pm 0.030\end{array}$ & $\begin{array}{l}7.299 \pm 0.014 \\
7.346 \pm 0.015 \\
5.535 \pm 0.010 \\
7.237 \pm 0.014\end{array}$ \\
\hline
\end{tabular}

* From elastic velocities [Peselnick and Robie, 1963].

$\dagger$ For shocks in $x$ and $y$ directions; principal stresses lie along rotated axes $x^{\prime}, y^{\prime}$, and $z^{\prime}$ [chapter 4, Cady 1946]. 


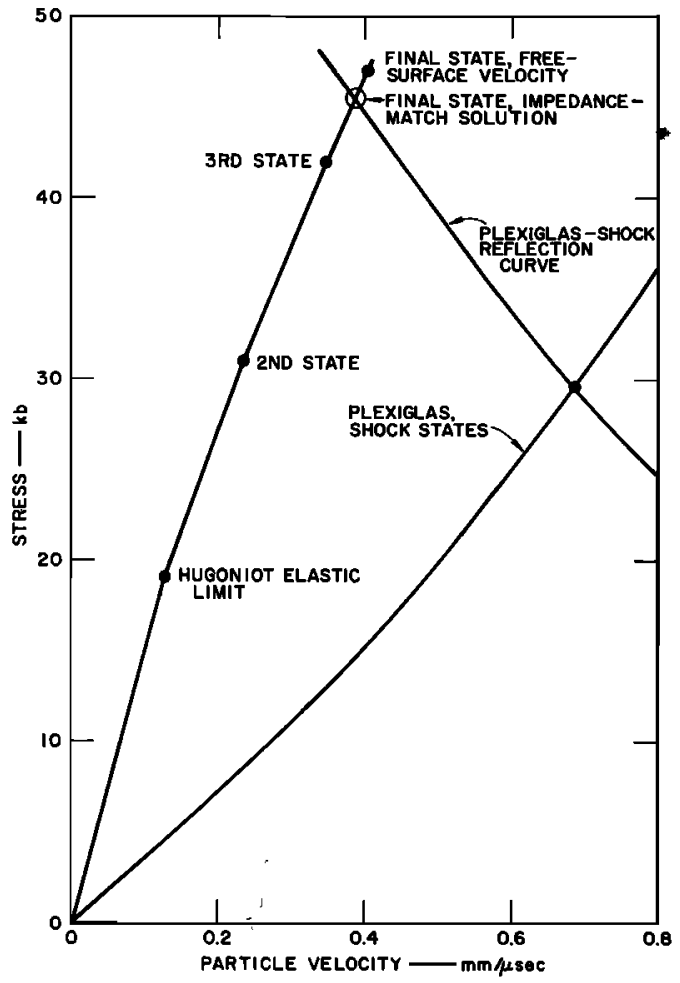

Fig. 18. Comparison of final state calculated by free-surface and impedance-match methods, $z$-cut calcite, shot $\mathbf{8 8 5 3}$.

shock with one or more succeeding shock fronts. One such simple model can be constructed by assuming that only an elastic wave and a second shock exist and that, upon reflection of the elastic wave at the free surface, the reflected rarefaction wave traveling at the elastic-wave velocity of the HEL impinges on the oncoming second shock. The amplitude of the second shock is thereby reduced (either to below the HEL, resulting in an elastic wave, or to above the HEL, resulting in an elastic wave corresponding to the HEL followed by a second wave) and the process is repeated. The consequences of this model were examined in detail for several of the experiments with calcite where complex free-surface velocity profiles were observed. This model was found to be untenable with respect to both arrival times and amplitudes of successive shock fronts. In another possible model a wave representing the HEL is assumed to be followed by a second shock due to a polymorphic phase transition, and a third wave is assumed to bring the material to its final state. Two waves may then be considered to interact with each other and the oncoming shock. Although a complex free-surface velocity profile may in principle be described in terms of such a model, it is difficult to demonstrate the model's uniqueness.

If in fact the observed changes in free-surface velocity above the HEL correspond to phase changes, the relative certainties of their existence may be critically considered. Clear evidence exists, in all orientations studied, of the existence of phase transitions at 30 to $32 \mathrm{~kb}$ and $95 \mathrm{~kb}$, these being the second and fourth instability (Figure 17). These were observed in eight and four different experiments, respectively. Evidence is less certain for a phase transition at the third instability; two reliable determinations for $z$-cut calcite are available, and three other experiments suggest its presence at about $45 \mathrm{~kb}$.

The differences indicated by the Hugoniot for calcite above $200 \mathrm{~kb}$ for the differently oriented specimens (Figure 17) are not considered well established.

Marble and limestone. Hugoniot data are obtained for polycrystalline calcium carbonate in the form of Yule and Vermont marbles (nonporous) and Solenhofen and Spergen limestone (porous). Hugoniots for marble are generally similar to that for calcite (Figure 19, Table 9). The HEL, varying from 10 to $15 \mathrm{~kb}$, is followed by three apparent transitions lying at approximately 22,40 , and $95 \mathrm{~kb}$. These transition states are not resolved in experiments with the twodimensional wedge, although in several cases complex shock-wave profiles are observed. The amplitude of the HEL of both $z$-cut calcite and Vermont marble is observed to decrease with shock travel. This so-called stress-relaxation phenomenon is also observed in quartz rocks. The apparent transition at $30 \mathrm{~kb}$ noted in the calcite experiments is not observed in the marble experiments.

The Hugoniots for porous limestones have HEL's which appear to decrease significantly with increasing initial porosity. Solenhofen and Spergen limestones with effective porosities of approximately 4 and $12 \%$, respectively, have HEL's of approximately 10 and $5 \mathrm{~kb}$. It is interesting that actual pores of Solenhofen limestone amount to less than $1 \%$. Minor impurities 


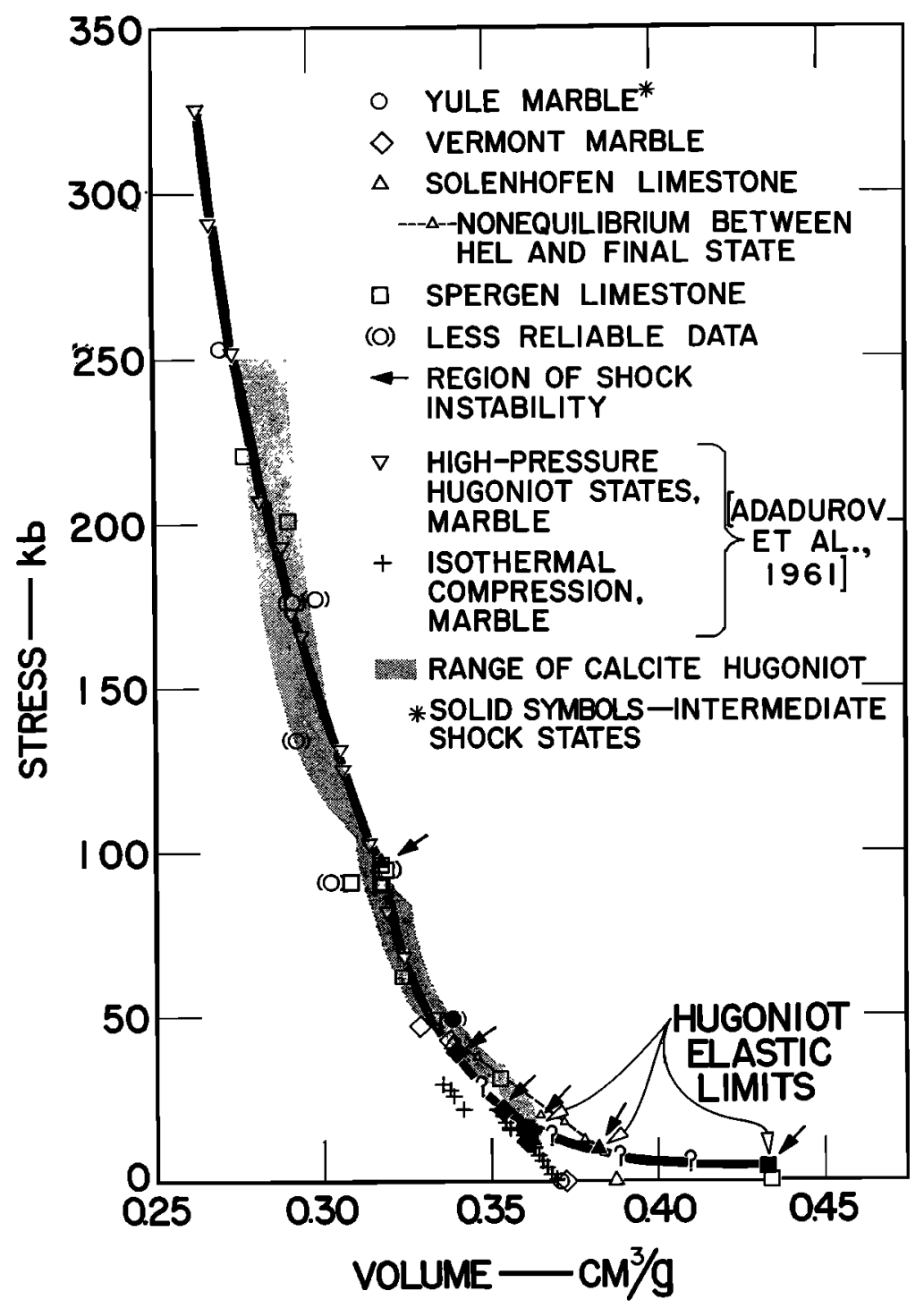

Fig. 19. Hugoniot, calcite rocks.

of lower density apparently affect the Hugoniot only at low stress levels, the Bugoniot tending toward that of the solid material at higher shock stresses in contrast to porous quartz rocks.

Multiple shock fronts observed above the HEL in calcite are not observed in porous carbonates. The presence of transitions must be inferred from the changes in slope of the Hugoniot. These are obtainable from the final states achieved by the shock compression, since the stability condition (6) is not violated.

Streak cutoff traces from inclined mirrors mounted on the free surfaces of porous limestone and of marble often appeared rounded rather than sharp and angular (this is observed to a lesser extent in the porous sandstones). The regions marked 1 and 2 on the rounded streak cutoff of Figure 20 are thought to represent stable shock states in Solenhofen limestone. State 1 corresponds to the HEL. The curvature between 1 and 2, approximately $0.3 \mu \mathrm{sec}$ in duration, may represent the compression risetime as the limestone transforms from state 1 to state 2. An alternative interpretation of the 
TABLE 9. Hugoniot Data, Calcite Rocks

\begin{tabular}{|c|c|c|c|c|c|c|}
\hline \multirow[b]{2}{*}{$\begin{array}{c}\text { Specimen; } \\
\text { Initial Density, } \\
\text { g/cm }\end{array}$} & \multirow{2}{*}{$\begin{array}{c}\text { Experimental Arrangement;* } \\
\text { Explosive Driver System; } \\
\text { Free-Surface Velocity, } \\
\mathrm{mm} / \mu \mathrm{sec}\end{array}$} & \multicolumn{2}{|c|}{$\begin{array}{l}\text { Intermediate Shock } \\
\text { States }\end{array}$} & \multicolumn{2}{|c|}{ Final Shock State } & \multirow[b]{2}{*}{$\begin{array}{l}\text { SRI } \\
\text { Shot } \\
\text { No. }\end{array}$} \\
\hline & & $\begin{array}{l}\text { Particle } \\
\text { Velocity, } \\
\mathrm{mm} / \mu \mathrm{sec}\end{array}$ & $\begin{array}{l}\text { Shock } \\
\text { Velocity, } \\
\mathrm{mm} / \mu \mathrm{sec}\end{array}$ & $\begin{array}{l}\text { Particle } \\
\text { Velocity, } \\
\mathrm{mm} / \mu \mathrm{sec}\end{array}$ & $\begin{array}{l}\text { Shock } \\
\text { Velocity, } \\
\mathrm{mm} / \mu \mathrm{sec}\end{array}$ & \\
\hline $\begin{array}{l}\text { Yule marble; } \\
2.697\end{array}$ & $\begin{array}{l}\text { A; } 5 \\
\text { A; } 5 \\
\text { B; } 12 ;(2.89) \\
\text { B; 12 } \\
\text { B; } 15 ;(2.870)\end{array}$ & $\begin{array}{l}(0.396) \\
(0.103)\end{array}$ & $\begin{array}{l}(4.63) \\
(5.73)\end{array}$ & $\begin{array}{l}(0.782) \\
(1.024) \\
(1.17) \\
(1.12) \\
1.59\end{array}$ & $\begin{array}{l}(3.537) \\
(4.478) \\
(5.52) \\
(5.83) \\
5.91\end{array}$ & $\begin{array}{l}8251 \\
8280 \\
7785 \\
7786 \\
8317\end{array}$ \\
\hline $\begin{array}{l}\text { Vermont marble; } \\
2.687\end{array}$ & $\begin{array}{l}A ; 6 ; 1.379 \\
A ; 6 ; 1.424\end{array}$ & $\begin{array}{l}0.086 \\
0.165 \\
0.123 \\
0.352\end{array}$ & $\begin{array}{l}5.262 \\
4.300 \\
4.718 \\
3.73\end{array}$ & $\begin{array}{l}0.378 \\
0.443\end{array}$ & $\begin{array}{l}3.791 \\
3.284\end{array}$ & 9257 \\
\hline $\begin{array}{l}\text { Solenhofen lime- } \\
\text { stone; } 2.581\end{array}$ & $\begin{array}{l}\mathrm{A} ; 6 ; 1.363 \\
\mathrm{~A} ; 5 ; 1.572\end{array}$ & $\begin{array}{l}0.073 \\
0.820\end{array}$ & $\begin{array}{l}5.330 \\
4.572\end{array}$ & $\begin{array}{c}0.441 \\
(1.238)\end{array}$ & $\begin{array}{l}3.094 \\
3.666\end{array}$ & $\begin{array}{l}9068 \\
9066\end{array}$ \\
\hline $\begin{array}{l}\text { Spergen lime- } \\
\text { stone; } 2.327\end{array}$ & $\begin{array}{l}\text { A; } ; ; 1.323 \\
\text { A; } 5 ; 1.572 \\
\text { A; } 5 ; 1.161 \\
\text { B; } 5 ; 1.51 \\
\text { B; } 5 ; 1.54 \\
\text { A; } 5 ; \\
\text { A; } 5 ; 1.51 \\
\text { A; } 12 ; \\
B ; 15 ; 2.94\end{array}$ & 0.046 & 3.888 & $\begin{array}{l}0.481 \\
1.025 \\
0.789 \\
0.965 \\
1.01 \\
1.020 \\
0.965 \\
1.62 \\
1.790\end{array}$ & $\begin{array}{c}2.634 \\
(4.00) \\
3.38 \\
3.94 \\
3.797 \\
4.11 \\
3.94 \\
5.21 \\
5.23\end{array}$ & $\begin{array}{l}9067 \\
9066 \\
8150 \\
8075 \\
8081 \\
8271 \\
8079 \\
8080 \\
8155\end{array}$ \\
\hline
\end{tabular}

* A, plane-wave inclined-mirror method.

$B$, plane-wave wedge method.

( ) Less reliable data.

finite rise-time is that it results from downward concavity of the Hugoniot (as is also suggested for calcite); this gives rise to nonsteady dispersive elastic shock. To calculate state 2 , we computed a series of intermediate nonequilibrium states corresponding to the curved portion of the trace by approximating the curve with a series of line segments. These states do not, however, lie along the Hugoniot, but rather along the Rayleigh line [Band, 1960, p. 698], as indicated in Figure 19. The resulting final state compares favorably with that obtained by using an impedance-match solution (Figure 21).

Discussion, Calcite and calcite rocks. Detection of what may be three, or possibly four, transitions along the Hugoniot for calcite below $100 \mathrm{~kb}$ is somewhat unexpected, although the isothermal compression curve of calcite (or marble) is known to be complex. Specific volumes and estimated temperatures achieved in the compression of calcite, marble, and limestone imply that, at least below $100 \mathrm{~kb}$, the observed transitions are related to the formation of the metastable $\mathrm{CaCO}_{3}$ polymorphs [Jamieson, 1957] rather than to the formation of aragonite, the form stable above $4 \mathrm{~kb}$. Isothermal compression data indicating two or (more probably) three metastable polymorphs occurring below $25 \mathrm{~kb}$ have been reported by Adadurov et al. [1961] and Bridgman [1939]. The isothermal compression curve displaying transitions to the metastable states is included in Figures 17 and 19. Whether aragonite, with a zero-pressure specific volume of $0.34 \mathrm{~cm}^{3} / \mathrm{g}$, is ultimately achieved at very high shock stresses is uncertain.

Equivalent hydrostatic pressure may be calculated in the relatively short shock-stress range corresponding to elastic behavior by assuming the validity of infinitesimal elastic constants. The elastic constants for calcite obtained by Peselnick and Robie [1963] are used to calculate the principal stresses corresponding to the shock- 


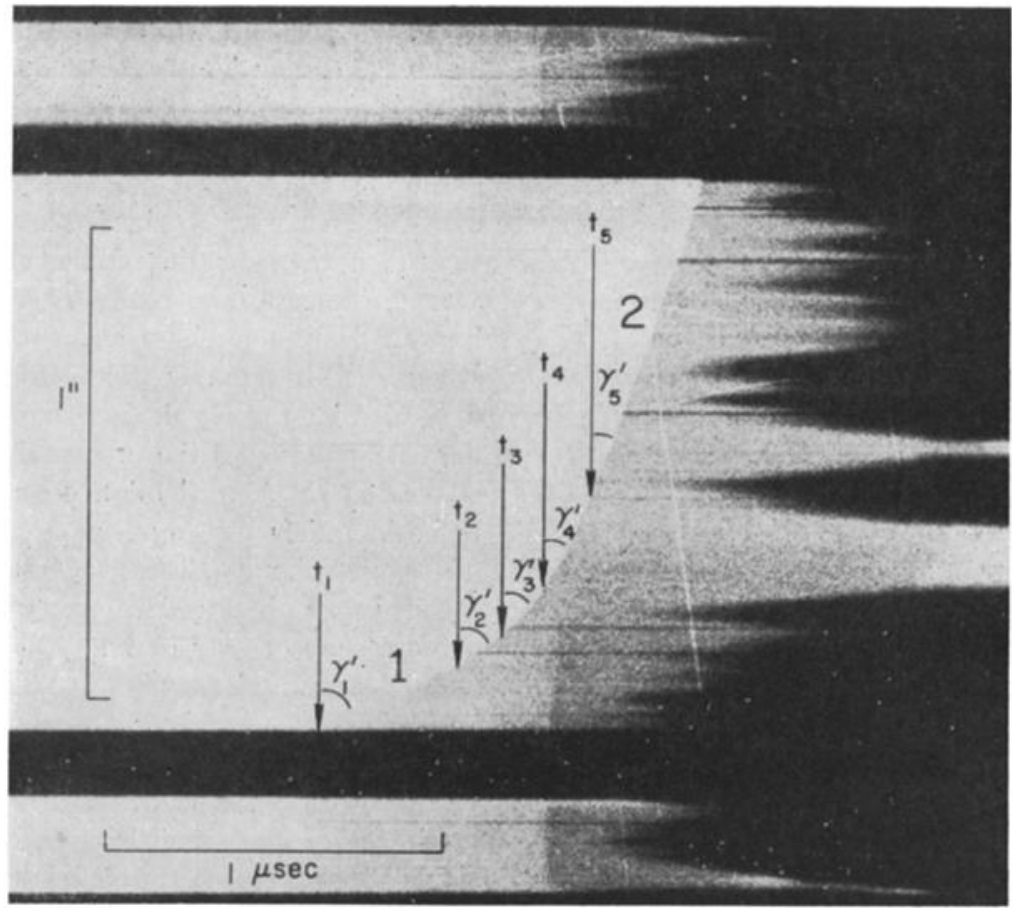

Fig. 20. Inclined-mirror cutoff, Solenhofen limestone, shot 9068 . State 1 is at $10-k b$ elastic limit, state 2 is at $42 \mathrm{~kb}, \gamma_{2}^{\prime}-\gamma_{i}^{\prime}$ refer to nonequilibrium states.

stress level at the HEL for different crystallographic orientations (Table 8). The average values of shock stresses corresponding to the calcite HEL for different orientations have a total range of $5.2 \mathrm{~kb}$. The variation with crystallographic direction is reduced to $2.7 \mathrm{~kb}$ when the HEL is expressed in terms of equivalent hydrostatic stress. The hydrostatic stress in calcite at the HEL, the average being taken in different directions, is $12.7 \mathrm{~kb}$. This value suggests a possible close relationship between yielding and polymorphism, since the latter occurs at both 11 and $16 \mathrm{~kb}$ at comparable specific volumes in static experiments. To examine the possible equivalence of apparent shock transitions with statically observed metastable transitions, it is worth while to consider briefly what the effect of elastic-plastic type of behavior [Duvall and Fowles, 1963] in calcite would be for the shock stress to continue to exceed the equivalent hydrostatic stress by the same amount as it, does at the HEL. From Table 8 this excess stress is 4 to $12 \mathrm{~kb}$, depending on orientation. If valid over a short stress range, this model implies that the second instability, occurring at 30 to $36 \mathrm{~kb}$, corresponds to the major volume change observed at $23 \mathbf{~ k b}$ in the static experiments at approximately the same volume. Notably, the second instability in calcite is the most clearly established of the apparent transitions, and the specific volume for the onset of this transition agrees with the isothermal result of Adadurov et al. [1961].

For marble, average values of the HEL and Poisson's ratio of $14 \mathrm{~kb}$ and $v=0.19$ are adopted, and an equivalent hydrostatic pressure of

$\bar{\sigma}=\sigma_{e}\{1-2[(1-2 \nu) / 3(1-\nu)]\}=6.9 \mathrm{~kb}$ is obtained at the shock-stress level of the HEL. This value, being below any of the transitions to the metastable forms of $\mathrm{CaCO}_{3}$ implies that in Vermont and Yule marbles, in contrast to calcite, the HEL is related to mechanical yielding rather than to polymorphism. On the assumption that the shock stress above the HEL continues to exceed the hydrostatic pressure by a nominal value, such as the $7.1 \mathrm{~kb}$ above, the 


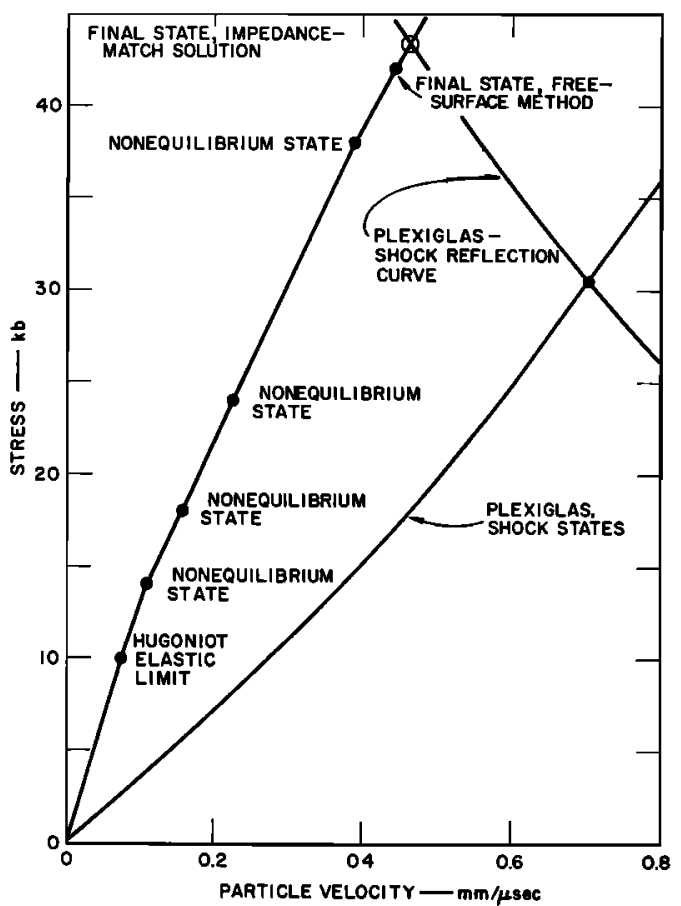

Fig. 21. Comparison of final states from freesurface and impedance-match methods, Solenhofen limestone, shot 9068.

apparent shock transitions in the marble do not relate simply to those observed statically. The transition observed at $22 \mathrm{~kb}$ in the marble may possibly be correlated with the $16-\mathrm{kb}$ static transition. The absence of the $30-\mathrm{kb}$ shock transition, prominent in calcite, may only be due to the paucity of data in this range.

Little evidence regarding the nature of the third instability (approximately $40 \mathrm{~kb}$ ) in calcite and marble is available, except that the transition appears to be difficult to detect both in shock and isothermal compression experiments. Bridgman [1939] did not report any transition in this range in runs up to $49 \mathrm{~kb}$.

An apparent fourth instability $(95 \mathrm{~kb})$ is consistently observed in both the single-crystal and polycrystalline experiments. It appears to result from a polymorphic transition. In a series of shock compression experiments in marble, Adadurov et al. [1961] observed a transition at approximately $150 \mathrm{~kb}$ with an estimated volume change of $0.15 \%$. This transition, which was not detected in our experiments, may actually represent the boundary between a triple and double shock front which might arise from the 95-kb transition. This supposition is not, however, supported by the data from the shock reflection experiments also performed by Adadurov et al. in which shock states off the normal Hugoniot were obtained. These data suggest that Grüneisen's ratio of the shock material sharply increases above $150 \mathrm{~kb}$, supporting the hypothesis that a phase change occurs at this stress level. In any case, the high-pressure shock data of Adadurov et al. correspond closely with the extrapolation of the present data for marble above $150 \mathrm{~kb}$. Also, the data for marble appear to be in satisfactory agreement with the range of stress-volume states achieved in calcite (shaded zone, Figure 19).

Plagioclase-bearing rocks. Hugoniots for San Gabriel anorthosite and Vacaville basalt have been obtained to pressures of 227 and $189 \mathrm{~kb}$, respectively (Figure 22 and Table 10 ). One exploratory experiment with nearly single-crystal specimens of albite and labradorite (shot 9231, Table 10) was also performed. The present data are plotted in terms of a relative volume because of different initial densities to allow comparison with the data for gabbro of Hughes and $\mathrm{Mc}$ Queen [1958]. The high plagioclase content of these mediums suggests that similar behavior is to be expected in shock compression. The scatter in both sets of data unfortunately precludes consideration of possible compositional dependence of the Hugoniots. The Hughes and McQueen data points shown in parentheses were obtained from rock specimens in which cracks caused abnormally low initial density.

The present data support the conclusion that below approximately $300 \mathrm{~kb}$ (and quite certainly at $150 \mathrm{~kb}$ ) the shock front consists of more than one wave; the first wave is overdriven above $300 \mathrm{~kb}$. Hughes and McQueen's data for pressures below $300 \mathrm{~kb}$ are not shown, since the particle velocity associated with the inferred first wave was not obtained. The present data give an amplitude of between 40 and $50 \mathrm{~kb}$ for the first wave in plagioclase and plagioclasebearing rocks, compared with an estimate of $150 \mathrm{~kb}$ which was the lower limit of the data available to Hughes and McQueen. The 40- to 50 -kb first wave is comparable to the amplitude of the HEL obtained for quartz, the only other silicate whose Hugoniot is reasonably well known. It is notable that this range of values 


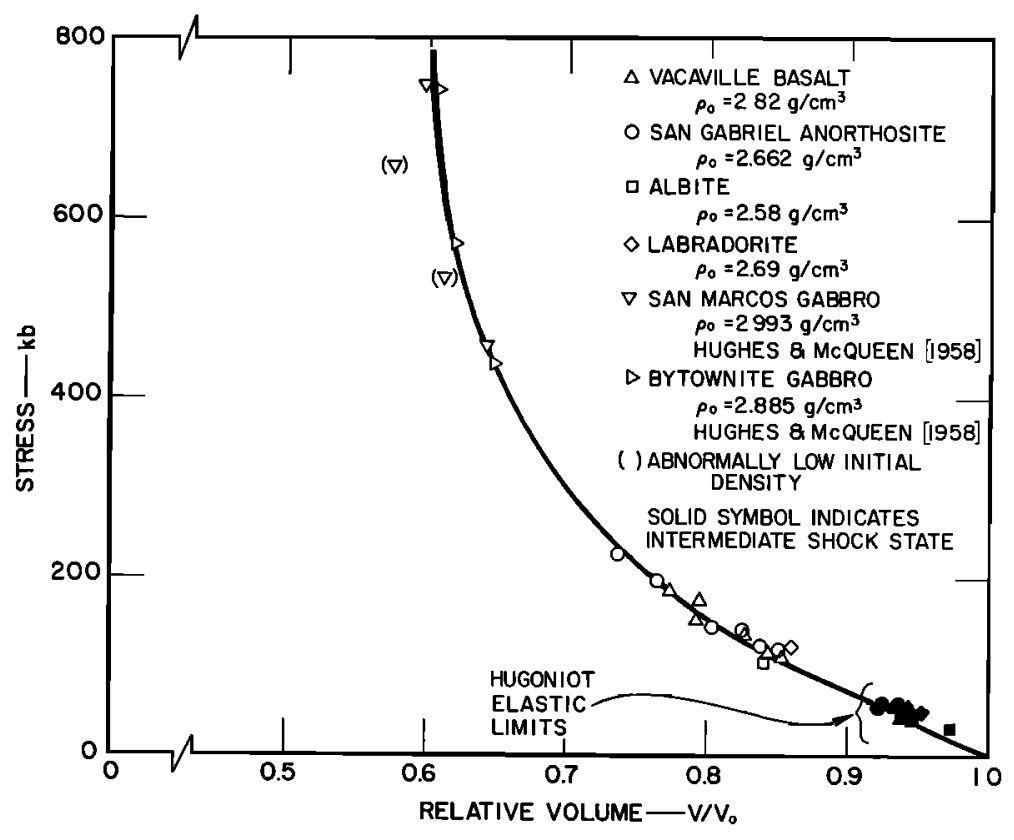

Fig. 22. Hugoniot, plagioclase-bearing rocks.

TABLE 10. Hugoniot Data, Plagioclase-Bearing Rocks

\begin{tabular}{|c|c|c|c|c|c|c|}
\hline \multirow[b]{2}{*}{$\begin{array}{c}\text { Specimen; } \\
\text { Initial Density; } \\
\text { g/cm }\end{array}$} & \multirow[b]{2}{*}{ 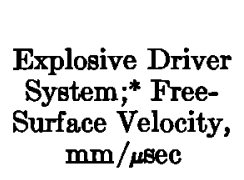 } & \multicolumn{2}{|c|}{ First Shock State } & \multicolumn{2}{|c|}{ Final Shock State } & \multirow[b]{2}{*}{$\begin{array}{l}\text { SRI } \\
\text { Shot } \\
\text { No. }\end{array}$} \\
\hline & & $\begin{array}{l}\text { Particle } \\
\text { Velocity, } \\
\text { mm/ } / \mu \text { sec }\end{array}$ & $\begin{array}{l}\text { Shock } \\
\text { Velocity, } \\
\mathrm{mm} / \mu \mathrm{sec}\end{array}$ & $\begin{array}{l}\text { Particle } \\
\text { Velocity, } \\
\mathrm{mm} / \mu \mathrm{sec}\end{array}$ & $\begin{array}{l}\text { Shock } \\
\text { Velocity, } \\
\mathrm{mm} / \mu \mathrm{sec}\end{array}$ & \\
\hline \multirow[t]{2}{*}{$\begin{array}{l}\text { San Gabriel } \\
\quad \text { anorthosite; } \\
2.662\end{array}$} & $\begin{array}{r}15 ; 2.955 \\
6 ; 1.404\end{array}$ & $\begin{array}{l}(0.261) \\
0.286 \\
0.293\end{array}$ & $\begin{array}{l}(6.17) \\
5.66 \\
5.67\end{array}$ & $\begin{array}{l}1.517 \\
1.320 \\
0.406\end{array}$ & $\begin{array}{l}5.63 \\
5.59 \\
3.75\end{array}$ & $\begin{array}{l}9099 \\
9101\end{array}$ \\
\hline & $\begin{array}{l}9 ; 1.560 \\
16\end{array}$ & $\begin{array}{l}0.317 \\
0.403 \\
0.378\end{array}$ & $\begin{array}{l}5.86 \\
5.40 \\
5.77\end{array}$ & $\begin{array}{l}0.858 \\
0.812 \\
1.029 \\
0.852\end{array}$ & $\begin{array}{l}5.34 \\
5.28 \\
5.18 \\
5.38\end{array}$ & $\begin{array}{l}9161 \\
9230\end{array}$ \\
\hline $\begin{array}{l}\text { Labradorite; } 2.69 \\
\text { Albite; } 2.59\end{array}$ & $9 ; 1.56$ & $\begin{array}{l}0.273 \\
0.188\end{array}$ & $\begin{array}{l}6.62 \\
6.60\end{array}$ & $\begin{array}{l}0.803 \\
0.802\end{array}$ & $\begin{array}{l}5.27 \\
4.80\end{array}$ & 9231 \\
\hline $\begin{array}{l}\text { Vacaville basalt; } \\
2.82\end{array}$ & $\begin{array}{l}16 ; 1.968 \\
9 ;(1.64) \\
12\end{array}$ & $\begin{array}{l}0.328 \\
0.291 \\
0.323\end{array}$ & $\begin{array}{l}5.43 \\
5.33 \\
5.55\end{array}$ & $\begin{array}{l}0.964 \\
0.906 \\
0.798 \\
0.764 \\
1.232 \\
1.124\end{array}$ & $\begin{array}{l}5.31 \\
5.19 \\
5.06 \\
5.12 \\
5.44 \\
5.40\end{array}$ & $\begin{array}{l}9159 \\
9160 \\
9232\end{array}$ \\
\hline
\end{tabular}

* Plane-wave inclined-mirror method.

( ) Less reliable values. 
for the HEL is considerably higher than those for metals, the only class of medium which had been studied at the time of the Hughes and McQueen experiments. The apparent change in slope of the Hugoniot observed by Hughes and McQueen is now attributed to the presence of an elastic wave, invalidating the former experimental points for pressures below approximately $300 \mathrm{~kb}$. Above this value only a single shock is present, and the previous data are believed to be valid.

Aside from possible dependence of the HEL on composition and initial volume-neither being presently well defined-the maximum elasticwave amplitude is observed to increase with increasing second-wave amplitude for the same specimen thickness. This is illustrated by the data for anorthosite (Table 10). Evidence for the occurrence of this so-called stress-relaxation behavior is less well defined in the case of basalt. The phenomenon appears to occur also in quartz rocks and calcite (see above).

The albite and labradorite specimens are so oriented that the shock plane is parallel to a cleavage plane in a material which may be termed 'single crystal' only in gross features, since it displays large volumes of profuse twinning. The lack of control in crystallographic direction and the elastic anisotropy observed in plagioclase minerals [Alexandrov and Ryzhova, 1962] suggest that the observed 20-kb difference in HEL value for labradorite and albite in shot 9231 may not be related to compositional variation. This stress difference is striking, however, because the specimens are subjected to the same incident shock and are of similar thickness.

Summary. Hugoniot equation-of-state data for quartzite, novaculite, sandstone, singlecrystal calcite, marble, limestone, basalt, and plagioclase were obtained in the stress range of 4 to $250 \mathrm{~kb}$, primarily by using planar, in-contact explosive assemblies. Two-dimensional wedge experiments yielded useful data for porous rocks only at lower stress levels. Shock states were computed from measured shock velocities and either specimen or driver plate free-surface velocities. Impedance-match solutions were used for porous rocks.

Polycrystalline nonporous quartz rocks haye Hugoniot elastic limits varying from approximately 40 to $90 \mathrm{~kb}$. Variations in the Hugoniot elastic limit appear more likely to result from differences in grain size and cementation character than from minor compositional variations. Above the Hugoniot elastic limit the shock states agree, within typical uncertainties of the order of $\pm 3 \%$ in pressure and relative volume, with both the low-pressure extrapolated shock (144 $\mathrm{kb})$ and isothermal (98 kb) compression data for quartz.

Sandstones (porosity 20 to $24 \%$ ) exhibit Hugoniot elastic limits between 4 and $8 \mathrm{~kb}$. Above the elastic limit the specific volumes achieved by sandstone decrease markedly, reaching the equivalent solid quartz volume at a stress of approximately $40 \mathrm{~kb}$. Measured freesurface velocities above the elastic limit suggest that the shock compression is highly irreversible, especially above $25 \mathrm{~kb}$. Above approximately $40 \mathrm{~kb}$ and up to compression states of $186 \mathrm{~kb}$, the shocked volumes are significantly less than either those of single-crystal quartz shocked to the same stress or that indicated by extrapolating the isothermal compression curve. Shock temperatures estimated by assuming thermal equilibrium in the shock state range from $250^{\circ} \mathrm{C}$ at $37 \mathrm{~kb}$ to $1450^{\circ} \mathrm{C}$ at $190 \mathrm{~kb}$. Both the observed volumes and the calculated temperatures suggest at least partial transition to coesite and, at high pressures, to stishovite. The shock stresses at which volumes less than quartz are achieved are considerably lower than the 144 -kb value proposed by McQueen et al. [1963] for the shockinduced quartz-stishovite transition in initially solid material. It appears possible that stishovite is forming directly from quartz upon shock compression; for this reason the stishovitequartz phase stability line was calculated by using the thermodynamic properties of $\mathrm{SiO}_{2}$ polymorphs estimated by Stishov [1963]. On the basis of zero-pressure volumes, the quartzstishovite phase line is given by $P=74.9+$ $0.0177 T$ ( $P$ in $\mathrm{kb}$ and $T$ in ${ }^{\circ} \mathrm{C}$ ). Under standard conditions, a quartz-stishovite internal energy difference of $10.2 \times 10^{\circ} \mathrm{ergs} / \mathrm{g}$ is computed; this is similar to $15.0 \times 10^{\circ} \mathrm{ergs} / \mathrm{g}$ obtained by McQueen et al.

Single-crystal calcite displays an elastic wave of 22-kb amplitude, followed by a series of complex apparent transitions occurring at 30,45 , and $95 \mathrm{~kb}$ and giving rise to four shock fronts between 42 and $51 \mathrm{~kb}$; these values vary slightly with specimen orientation. At the calcite elastic 
limit, the computed mean hydrostatic stress of $13 \mathrm{~kb}$ and the observed specific volume suggest that the yielding is induced by transition to one of the series of metastable polymorphs observed by Bridgman [1939] and Adadurov et al. [1961]. In marble and limestone, above elastic limits of 5 to $15 \mathrm{~kb}$, transitions appear at 22,45 , and 90 $\mathrm{kb}$. The elastic limit in marble appears to be related to mechanical yielding rather than to polymorphism, since the estimated hydrostatic pressure at the average elastic limit is $6.9 \mathrm{~kb}$; this is considerably below the transitions to metastable forms of $\mathrm{CaCO}_{3}$. The apparent shock transitions in marble do not appear to relate simply to those observed statically. The apparent transition at $95 \mathrm{~kb}$, which is consistently observed in both single-crystal and polycrystalline experiments, may be related to the transition detected at approximately $150 \mathrm{~kb}$ by Adadurov et al. The shock reflection experiments performed by Adadurov et al. suggest that Grüneisen's ratio for the shocked material sharply increases at $150 \mathrm{~kb}$; in contrast, present data suggest that this transition may represent the boundary between a triple and double shock front arising from the 95-kb transition. Regardless of interpretation, the data points for calcite rocks are in satisfactory agreement with the Adadurov et al. data for marble and are within the range of stress-volume states achieved by calcite.

Above eslastic limits of approximately $50 \mathrm{~kb}$, present data for basalt and for various plagioclases and previously reported data for two gabbros above $300 \mathrm{~kb}$ [Hughes and McQueen, 1958] lie on the same Hugoniot when plotted in terms of relative volume. The previously observed slope change of the Hugoniot for gabbro is believed to result from an elastic wave of perhaps $50-\mathrm{kb}$ amplitude which is overdriven at approximately $300 \mathrm{~kb}$.

Elastic-wave amplitudes appear to decay with propagation distance-presumably a stress-relaxation phenomenon-in all the nonporous rocks and minerals studied. In quartzite, the effect is directly observed in plane-wave wedge experiments, whereas in calcite, marble, and plagioclase rocks indirect evidence is derived from lower values of the elastic limit associated with longer shock propagation paths.

Appendix A, Inclined mirror determination of free-surface velocity. The inclined-mirror (also

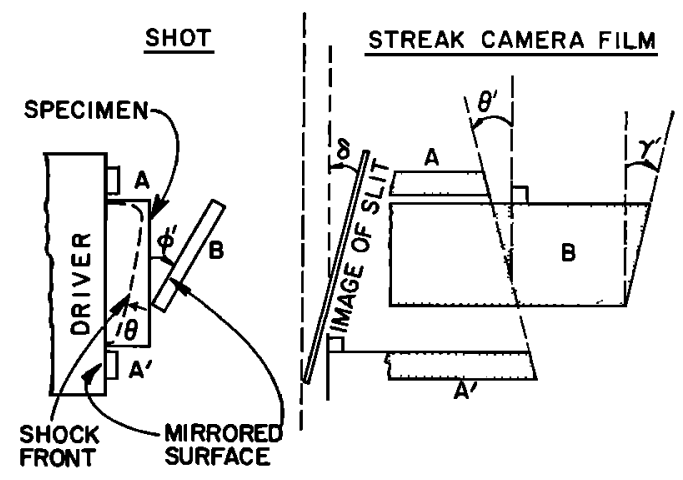

Fig. 1a. Angular relations between plane-wave inclined-mirror assembly and resulting streak camera record. Specimen shock tilt $\theta$ produces film shock tilt $\theta^{\prime}$. Mirror B inclined at angle $\phi^{\prime}$ produces film cutoff angle $\gamma^{\prime}$.

the inclined-argon-gap [Walsh and Christian, 1955] and slanted-resistor [Barker, 1961]) method for continuously recording the velocity of a free surface depends critically upon the condition that the impact of mirror with the free surface be supersonic. Thus the angle of mirror inclination must satisfy $\phi^{\prime}>\sin ^{-1} u_{t} / U$. In this case, $U$ is shock velocity in either the specimen or inclined mirror, whichever is greater. Although the free surface of the specimen is assumed to move in the direction normal to the undisturbed surface, ${ }^{1}$ the shock tilt in the specimen is taken into account to the extent of calculating an effective mirror angle given by

$$
\phi=\phi^{\prime}+\Delta \phi
$$

The angles in Figure 1 $a$, with the exception of $\gamma^{\prime}$, are all small, and suitable approximations are made.

The value of streak cutoff angle, $\gamma$, corrected for slit nonorthogonality, is

$$
\tan \gamma=\cos \delta\left(\tan \gamma^{\prime}+\tan \delta\right)
$$

The shock tilt correction to the inclined-mirror angle appropriate to the experiment sketched in Figure $1 a$ is

$$
\Delta \phi=\frac{m}{W} \theta^{\prime} u_{f}
$$

1 Upon incidence of a slightly oblique shock, the normal to the free surface and the direction of motion are not in coincidence with each other or with the normal to the undisturbed surface. 


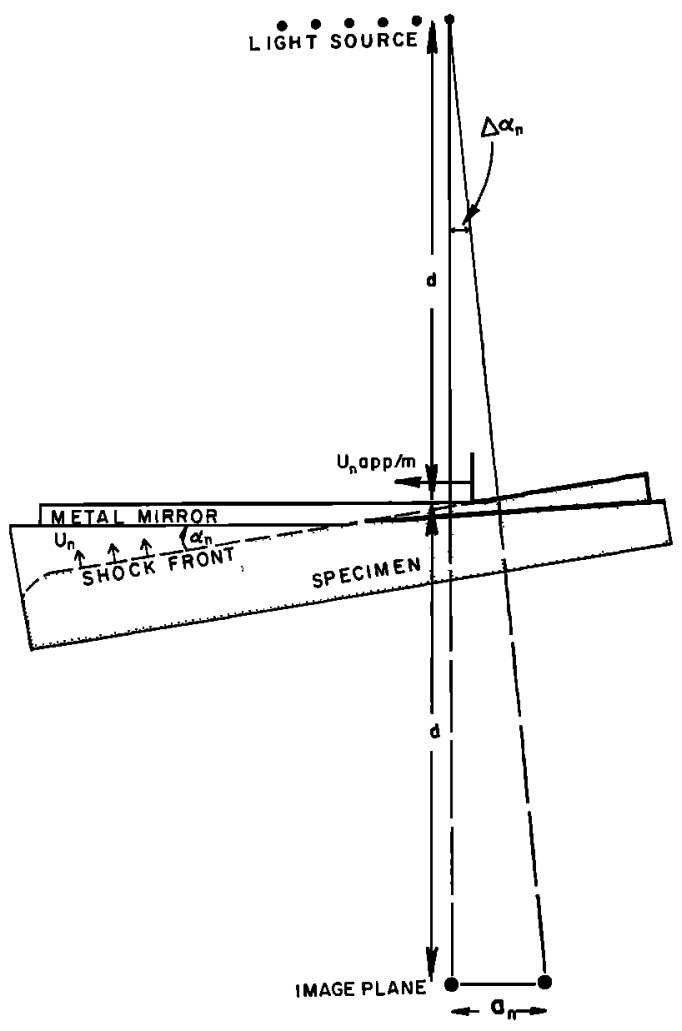

Fig. 1b. Optical lever geometry; oblique shock incident at angle $\alpha_{n}$ results in apparent velocity $U_{n, \mathrm{app} / m}$ and image displacement $a_{n}$.

The free-surface velocity is

Hence

$$
u_{f}=\frac{W}{m} \frac{\tan \phi}{\tan \gamma}
$$

$$
\Delta \phi \approx \frac{\tan \phi^{\prime}}{\tan \gamma} \theta^{\prime}
$$

Generally, $u_{t}$ is calculated by first obtaining the corrected value of $\gamma$ from (2-A); since the angle $\delta$ is usually less than $1^{\circ}$, the correction to $\gamma^{\prime}$ amounts to less than $2 \%$. Then $\Delta \phi$ is calculated, by using in (4-A) the uncorrected angle $\phi^{\prime}$. Since $\theta^{\prime}$ is typically less than $1^{\circ}$ and frequently less than $0.1^{\circ}, \phi^{\prime}$ is of the order of $5^{\circ}$ and $\gamma^{\prime}$ is 15 to $60^{\circ}, \Delta \phi$ amounts to less than $1 / 3^{\circ}$ or perhaps $6 \%$ of $\phi$. Finally, $u_{f}$ is calculated from corrected values of $\gamma$ and $\phi$. Iteration to obtain a closer value for $\Delta \phi$ is not usually required.

Experimental uncertainties in free-surface velocity for values above approximately 0.5 $\mathrm{mm} / \mu \mathrm{sec}$ arise mainly from errors in measuring the angle $\gamma\left( \pm 1^{\circ}\right)$. This error corresponds to approximately $\pm 2.5 \%$ in free-surface velocity. For free-surface velocities below $0.5 \mathrm{~mm} / \mu \mathrm{sec}$, an additional error due to the uncertainty in $\theta^{\prime}$ can increase the free-surface velocity error to $\pm 4 \%$.

Appendix B, Free-surface measurements for multiwave oblique shocks. The optical lever method for measurement of the free-surface velocity produced by a slightly oblique shock front incident on a specularly reflecting surface is described by Fowles [1961a]. The oblique shock-free surface interaction tilts the free surface; this tilting displaces the specular image of a grid light source on the film a distance $m a_{n}$ (Figure 1b). From the geometry of Figure $1 b$ the turning angle

$$
\Delta \alpha_{n}=a_{n} / 2 d
$$

The relation between $\alpha_{n}, \mathrm{U}_{n, \text { app }} / m$, and $\Delta \mathrm{u}_{n}$ behind the shock is obtained by considering the free-surface interaction in a two-dimensional flow diagram (Figure 2b) [Courant and Friedrichs, 1948, p. 297]. The streamline flow, $S_{n}$, lies

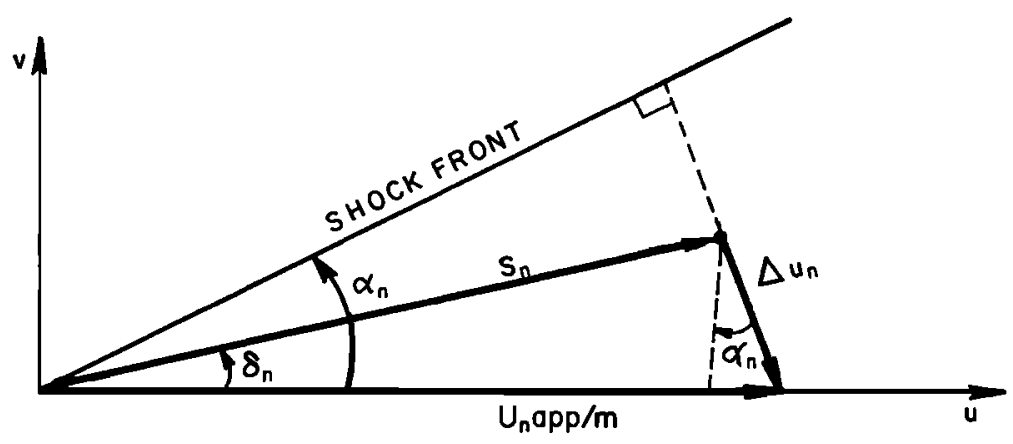

Fig. 2b. Two-dimensional flow diagram. Shock incidence at angle $\alpha_{n}$ results in streamline along $S_{n}$ giving net change in particle velocity $\Delta u_{n}$. 
at an angle $\delta_{n}$ relative to the apparent velocity $\mathrm{U}_{n \text {, app }} / m$; the origin of coordinates is at the point of intersection of the shock front with the free surface. The change in particle velocity in the shocked material upon arrival of the $n$th shock front is given by

$$
\Delta \mathbf{u}_{n}=\mathbf{U}_{n, \text { apd }} / m-\mathbf{S}_{n}
$$

From the geometry of Figure $2 b$,

$$
\begin{array}{r}
\tan \delta_{n}=\frac{\Delta u_{n} \cos \alpha_{n}}{U_{n, \mathrm{app}} / m-\Delta u_{n} \sin \alpha_{n}} \\
\Delta u_{n}=\frac{U_{n, \mathrm{app}} \sin \delta_{n}}{m \cos \left(\alpha_{n}-\delta_{n}\right)}
\end{array}
$$

The free-surface approximation implies that the change in streamline direction, $\delta_{n}$, is the same for the shock as the reflected rarefaction wave, i.e.,

$$
\Delta \alpha_{n}=2 \delta_{n}
$$

Substitution of (1-B) and (4-B) into (3-B) yields, for the change in particle velocity in the mirror,

$$
\Delta u_{n}=\frac{U_{n, \text { app }} \sin \left(\frac{a_{n}}{4 d}\right)}{m \cos \left(\alpha_{n}-\frac{a_{n}}{4 d}\right)}
$$

It should be noted that $m a_{n}$ is the total displacement of the film streak in the direction normal to the undisturbed streak, and the wedge angle used in (9) and (5-B) must be corrected for the tilt of the free surface produced by the previous $(n-1)$ th shock.

$$
\alpha_{n}=\alpha_{n-1}-\Delta \alpha_{n-1}
$$

Although the effect of the change in direction of the free surface produced by the $(n-1)$ th shock on the determination of $U_{n}$ is treated, the effect on $U_{n}$ of the free-surface displacement resulting from the free-surface velocity $2\left(\Delta u_{n-1}\right)$ is neglected.

Acknowledgments. This research was supported through Air Force Cambridge Research Laboratories, contract AF 19(604)-8419, and Defense Atomic Support Agency contract DA-49-146-XZ277 as part of the Advanced Research Projects Agency's project Vela-Uniform. The program was initiated by Dr. D. R. Grine, who performed much of the early significant work. Mr. C.F. Petersen and Dr. J. C. Jamieson also made important contributions to the study. We are grateful for scientific discussion and guidance provided by Drs. G. R. Fowles and G. E. Duvall and the thoughtful criticisms of the manuscript by Drs. D. G. Doran and P. Moravek. Rock specimens and descriptions provided by H. J. Moore, U. S. Geological Survey, were helpful. We appreciate use of a translation of Stishov's [1963] paper provided by Dr. F. R. Boyd, Carnegie Institution of Washington.

\section{REFERENCES}

Adadurov, G. A., D. B. Balashov, and A. N. Dremin, A study of the volumetric compressibility of marble at high pressures, Bull. Acad. Sci. USSR, Geophys. Ser., English Transl., 5, 463-466, 1961.

Alexandrov, K. S., and T. V. Ryzhova, Elastic properties of rock-forming minerals: III feldspars, Bull. Acad. Sci. USSR, Geophys. Ser., English Transl, 2, 129-131, 1962.

Band, W., Studies in the theory of shock propagation in solids, J. Geophys. Res., 65, 695-719, 1960.

Barker, L. M., Measurement of free-surface motion by the slanted resistor technique, Sandia Corp. SCDR 78-61, 1961.

Birch, F., Elasticity and constitution of the earth's interior, J. Geophys. Res., 57, 227-286, 1952.

Boyd, F. R., and J. L. England, The quartz-coesite transition, J. Geophys. Res., 65, 749-756, 1960.

Brace, W. F., and J. B. Walsh, Some direct measurements of the surface energy of quartz and orthoclase, Am. Mineralogist, 47, 1111-1122, 1962.

Bridgman, P. W., The high pressure behavior of miscellaneous minerals, Am. J. Sci., 36, 7-18, 1939.

Bridgman, P. W., The compression of 39 substances to $100,000 \mathrm{~kg} / \mathrm{cm}^{2}$, Proc. Am. Acad. Arts Sci., $76,55-70,1948$.

Cady, W. G., Piezoelectricity, MeGraw-Hill Book Company, New York, 1946.

Courant, R., and K. O. Friedrichs, Supersonic Flow and Shock Waves, Interscience Publishers, New York, 1948.

Duvall, G. E., Stability of shock waves, Colloq. Intern. Centre Natl. Rech. Sci., Paris, Sur Les Ondes de Detonation, Aug. 28-Sept. 2, 1961.

Duvall, G. E., Concepts of shock wave propagation, Bull. Seismol. Soc. Am., 52, 869-893, 1962.

Duvall, G. E., and G. R. Fowles, Shock waves, chapter 9, High Pressure Physics and Chemistry, vol. 2, edited by R. S. Bradley, Academic Press, New York, 1963.

Fowles, G. R., Shock wave compression of hardened and annealed 2024 aluminum, J. Appl. Phys., 92, 1475-1487, 1961 .

Fowles, G. R., Shock wave compression of quartz, Ph.D. thesis, Stanford University, June 1961b.

Hughes, D. S., and R. G. McQueen, Density of basic rocks at very high pressures, Trans. Am. Geophys. Union, 39, 959-965, 1958. 
Jamieson, J. C., Introductory studies of high-pressure polymorphism to 24,000 bars by X-ray diffraction with some comments on calcite II, $J$. Geol., 65, 334-343, 1957.

Johannsen, A., A Descriptive Petrography of the Igneous Rocks, 2nd ed. University of Chicago Press, 1939.

Katz, S., D. G. Doran, and D. R. Curran, Hugoniot equation of state of aluminum and steel from oblique shock measurement, $J$. Appl. Phys., 30, 568-576, 1959.

Kelley, K. K., Contributions to the data on theoretical metallurgy, Bull. 476, Bureau of Mines, U. S. Department of Interior, 1949.

Kormer, S. B., A. I. Funtikov, V. D. Urlin, and A. N. Kolesnikova, Dynamic compression of porous metals and the equation of state with variable specific heat at high temperatures, Soviet Phys. JETP, English Transl., 11, 766-775, 1960.

McQueen, R. G., J. N. Fritz, and S. P. Marsh, On the equation of state of stishovite, J. Geophys. Res., 68, 2319-2322, 1963.

Murnaghan, F. D., Finite Deformation of an Elastic Solid, J. Wiley \& Sons, New York, 1951.

Peselnick, L., and R. A. Robie, Elastic constants of calcite, J. Appl. Phys., 34, 2494-2495, 1963.
Rempel, J. R., Shock attenuation in elastic rigid foams, Stanford Res. Inst. Proj. PGU-\$581, Final Rept., 1963.

Rice, M. H., R. G. McQueen, and J. M. Walsh, Compression of solids by strong shock waves, Solid State Physics, vol. 6, edited by F. Seitz and D. Turnbull, pp. 1-63, Academic Press, New York, 1958.

Ringwood, A. E., Mineralogical constitution of the deep mantle, J. Geophys. Res., 67, 4005-4010, 1962.

Selar, C. B., A. P. Young, L. C. Carrison, and C. M. Schwartz, Synthesis and optical crystallography of stishovite, a very high pressure polymorph of $\mathrm{SiO}_{2}, J$. Geophys. Res., 67, 40494054, 1962.

Stishov, S. M., Equilibrium line between coesite and rutile-like modification of silica, Dokl. Acad. Nauk SSSR, 148, 1186-1188, 1963.

Wackerle, J., Shock-wave compression of quartz, J. Appl. Phys., 33, 922-937, 1962.

Walsh, J. M., and R. H. Christian, Equation of state of metals from shock wave measurements, Phys. Rev., 97, 1544-1556, 1955.

(Manuscript received June 8, 1964; revised August 26, 1964.) 